\title{
Altruism and Burnout: Long Hours in the Teaching Profession
}

Department of Economics Working Paper Series

\section{Dora Gicheva}

University of North Carolina at Greensboro

August 2020

Working Paper 20-07

economics.uncg.edu 


\title{
Altruism and Burnout: Long Hours in the Teaching Profession
}

\author{
Dora Gicheva*
}

August 2020

\begin{abstract}
This paper addresses the question of why many public school teachers work substantially more hours than required by contract given that the elasticity of earnings with respect to hours is close to zero in this occupation. I introduce a theoretical framework in which some public sector employees are intrinsically motivated to supply effort above the level stipulated by their contract, while others have low productivity and require high effort to maintain the minimally required level of output. In this setting, high levels of effort can be indicative of either altruism or low productivity. Because intrinsically motivated employees derive higher utility from working in the public sector, they are less likely to exit it. Over time, selection makes high levels of effort more strongly predictive of altruism than of low ability. I show empirical evidence consistent with this model from the market for public school teachers, where I define effort as working hours. At very low levels of experience, there is little or no relationship between weekly hours and the probability of remaining in teaching or a subjective measure of intrinsic motivation. These correlations become more positive as teaching experience increases. Similarly, hours are positively related to self-reported burnout at low levels of experience, but the relationship is reversed for teachers who have been in the profession longer.
\end{abstract}

JEL Codes: I21, J22, J45

Keywords: intrinsic motivation, working hours, teachers, public sector labor markets

${ }^{*}$ Department of Economics, University of North Carolina at Greensboro, PO Box 26170, Greensboro, NC 27402, USA. E-mail: d_gichev@uncg.edu. I am grateful to Daniel Hamermesh, Julie Hotchkiss, and participants in the 2018 IZA World Labor Conference and 2019 SNAG Micro Labor Workshop for helpful comments. 


\section{Introduction}

Whereas the short- and long-term career benefits of supplying long hours in the private sector have been analyzed in a number of studies, not much is known about the labor supply decisions and subsequent career outcomes of nonprofit workers. Pro-social motivation seems to drive some employees in the public sector to donate hours or effort. This general trend has been analyzed theoretically (Delfgaauw and Dur 2008) and documented empirically (Gregg, Grout, Ratcliffe, Smith and Windmeijer 2011); Rebitzer and Taylor (2011) provide further review of the related literature.

I examine in this study labor supply in the nonprofit sector in the context of the labor market for public school teachers. In addition to this being an occupation with high potential for pro-social motivation, it is also one where understanding how to recruit and retain motivated and effective workers is particularly important (e.g. Stinebrickner 2002). The teacher labor market is large and salary schedules are mostly fixed, meaning that there is little monetary payoff to high effort and long working hours. ${ }^{1}$ Yet, during the school year teachers report working hours similar to those for college-educated workers in other occupations that are more likely to offer monetary rewards for higher levels of labor supply (Drago, Caplan, Costanza, Brubaker, Cloud, Harris, Kashlan and Riggs 1999, Stoddard and Kuhn 2008). Stress and burnout are recognized as common problems among teachers (Greenberg, Brown and Abenavoli 2016) and may have negative impact on student achievement (Arens and Morin 2016).

This paper attempts to reconcile the low level of incentive pay in teaching with the observed high levels of effort among some workers in this occupation. I introduce a theoretical framework in which some public sector employees are intrinsically motivated to supply effort above the level stipulated by their contract, while others have low productivity and require

\footnotetext{
${ }^{1}$ Podgursky (2011) offers an overview of teacher compensation practices in the United States.
} 
high effort to maintain the minimally required level of output. In this setting, high levels of effort can be indicative of one of two things: altruism or low productivity. Because intrinsically motivated employees derive higher utility from working in the public sector, they are less likely to leave. Over time, high levels of effort become more strongly predictive of altruism than of low ability. I test the model empirically, defining effort as working hours.

The theoretical framework is contingent on the assumption that immediate monetary rewards or longer-term career concerns are not a compelling reason for teachers to supply long working hours. Using data from the Census and American Community Survey (ACS), I explore whether the elasticity of annual earnings with respect to weekly hours is close to zero for teachers and how it compares to the elasticity for professional occupations in the for-profit sector. I then use data from three waves of the Schools and Staffing Survey (SASS) conducted by the National Center for Education Statistics, which surveys teachers from a nationally representative sample of schools, to document the observed relationship between weekly hours and the probability of remaining in teaching at different levels of experience. I also use subjective survey questions designed to measure teacher motivation to test whether weekly hours become more positively correlated with motivation over time.

The findings contribute to our understanding of the determinants of hours of work for teachers and public sector employees in general. Time diary data suggest that it is common for teachers to work additional hours in the evenings and on weekends (Drago et al. 1999, Krantz-Kent 2008), but the existing literature does not make it clear what incentivizes them to do so. There is conflicting evidence as to whether teachers' labor supply responds to incentives built into the school system. Stoddard and Kuhn (2008) show that while teachers' average weekly work hours have risen steadily, there is no evidence that education reforms result in longer working hours, or the effect is very small. Hoxby (2002) demonstrates that teachers work more hours in schools located in areas with more school choices available to 
parents. Lavy (2009) shows evidence that high school teachers in Israel increase the time they spend on instruction when their students' exam performance is tied to monetary incentives. Gershenson (2016) uses administrative data from North Carolina to show that teachers are absent fewer days when their school fails to make adequate yearly progress under the No Child Left Behind Act. A number of recent studies have examined the relationship between incentive pay and other dimensions of teacher effort, ${ }^{2}$ but none of them analyze labor supply responses. In addition to showing evidence that teacher pay is very weakly related to hours worked, the current study is the first to link teacher labor supply explicitly to intrinsic motivation.

This paper also adds to the literature on teacher turnover. Previous research such as Murnane and Olsen $(1989,1990)$ and Dolton and van der Klaauw $(1995,1999)$ has demonstrated that potential earnings in other sectors play a role, although more recent studies that rely on administrative data do not find strong support for the claim that nonteaching earnings have strong impact on teacher exits (Podgursky, Monroe and Watson 2004, Scafidi, Sjoquist and Stinebrickner 2005). Working conditions and satisfaction with teaching have also been found to be important determinants of teacher turnover (Ingersoll 2001, Hanushek, Kain and Rivkin 2004). The contribution of this study is to analyze how teacher motivation and working hours are related to the probability of staying in the profession.

The following section presents the theoretical framework that motivates the empirical analysis. Section 3 uses data from the Census/ACS to explore the extent to which annual earnings among teachers increase with hours, compared to workers in other professional occupations. Section 4 provides more details about the SASS data, which I use in Section 5 to test the theoretical predictions. Section 6 concludes.

\footnotetext{
${ }^{2}$ See for example Podgursky and Springer (2007a), Podgursky and Springer (2007b), Atkinson, Burgess, Croxson, Gregg, Propper, Slater and Wilson (2009), and Goodman and Turner (2013)
} 


\section{Theoretical Framework}

The theoretical setup in this section assumes that the labor market is comprised of a public and private sectors. I do not model workers' choices and outcomes in the private sector and for the sake of simplicity assume away heterogeneity in the private sector; this assumption is relaxed later on without affecting the main predictions of the model. Workers are heterogeneous along two dimensions: productivity and intrinsic motivation in the public sector. A number of recent studies, such as Gaynor, Rebitzer and Taylor (2004), Heyes (2005), Besley and Ghatak (2005), Besley and Ghatak (2006), Prendergast (2007), and Delfgaauw and Dur (2008) have examined theoretically and empirically the labor market implications of worker heterogeneity in intrinsic motivation. Macartney, McMillan and Petronijevic (2018) show that teacher value added in particular can be separated into intrinsic ability and effort, with the difference being that the latter responds to incentives, while the former does not. Productivity in the model is observed by employers, so there is no screening or signaling, but there is a minimum required level of output in the public sector that each worker has to produce.

All workers in the model start off as public sector employees and remain in the public sector until they are laid off or until they choose to leave voluntarily. ${ }^{3}$ Public sector output for worker $i$ conditional on her level of effort $e$ is verifiable and given by

$$
q_{i}(e)=a_{i} e
$$

where $a_{i}$ measures inherent ability or productivity. Wages in the public sector are fixed at

\footnotetext{
${ }^{3}$ An alternative assumption is that workers receive a noisy signal of their utility of public sector employment prior to entering the labor market and gradually learn about their true utility parameters. The data do not allow me to examine empirically selection into public sector jobs, but I show in Section 5 that some of the empirical relationships are stronger when teachers with fewer than three years of experience are excluded from the sample. This is consistent with some degree of learning about one's utility from public sector employment.
} 
$\tilde{w}$, and workers who produce output below the minimum required level $\bar{q}$ are laid off and receive unemployment utility below their reservation value. Some workers have public service motivation and derive utility from exerting effort in public sector jobs. Instantaneous utility in this sector is given by

$$
U_{i}(e)=\tilde{w}+\gamma_{i} V(e)-C(e)
$$

where $\gamma_{i} \geq 0$ and $V^{\prime}(\cdot)>0, V^{\prime \prime}(\cdot) \leq 0 .{ }^{4}$ The cost of exerting effort is the same for all workers, and the usual assumptions that $C^{\prime}(\cdot)>0$ and $C^{\prime \prime}(\cdot)>0$ apply.

Similarly to Delfgaauw and Dur (2008), I assume that there are three types of workers in the population: regular $(r)$, motivated $(m)$, and low-productivity $(l)$. It holds that $0<$ $a_{l}<a_{r}=a_{m}$ and $0=\gamma_{l}=\gamma_{r}<\gamma_{m}$. Workers know their type $\gamma$; output, effort, and thus $a_{i}$ are observed by everyone. Without loss of generality, it is assumed that the share of workers of each type starts off the same.

Regular and low-productivity workers produce $\bar{q}$ in public-sector jobs, exerting effort levels $e_{r}^{*}=\bar{q} / a_{r}$ and $e_{l}^{*}=\bar{q} / a_{l}$ respectively. Assuming that $e_{m}^{*}>\bar{q} / a_{m}$, where $e_{m}^{*}$ solves $C^{\prime}\left(e_{m}^{*}\right)=\gamma_{m} V^{\prime}\left(e_{m}^{*}\right)$, motivated workers produce more than the minimum required output, even though there is no monetary reward for output above $\bar{q}$. The corresponding value of a public-sector job for worker $i$ is

$$
V_{i}^{*}=\tilde{w}+\gamma_{i} V\left(e_{i}^{*}\right)-C\left(e_{i}^{*}\right)
$$

It will be the case that $V_{m}^{*}>V_{r}^{*}>V_{l}^{*}$.

In this model, types $m$ and $l$ may both exert high levels of effort but for different reasons: effort increases utility for type $m$, while low-productivity workers need to exert higher effort

\footnotetext{
${ }^{4}$ This utility function is in line with the idea of impure, or "warm-glow" altruism because individuals derive utility directly from their actions, not from the level of output they provide to society (Andreoni 1989, Francois and Vlassopoulos 2008).
} 
than workers of type $r$ in order to attain the minimum required level of output $\bar{q}$. The rest of this section assumes that $e_{m}^{*}=e_{l}^{*}=e_{H}$, which makes motivated and low-productivity workers observationally equivalent on effort.

In each period $t$ public sector employees receive an outside option worth $\bar{V}(t)$ drawn from a known common distribution $F_{t}(\cdot)$. Outside options include employment in the private sector, where motivation does not play a role, or time at home. ${ }^{5}$ Allowing workers to receive an outside offer prior to the start of the first period is one way to incorporate selection into the public sector. Workers leave the public sector if $V_{i}^{*}<\bar{V}(t)$. It is likely that the distribution of outside options changes over time; for example, outside options generally become more attractive as workers accumulate enough experience to be eligible for pension benefits. The key assumption here is that the distribution of outside offers at a given level of experience $t$ is the same for all types of workers. To simplify the exposition, I assume that $F_{t}(\cdot)$ is stationary and denoted by $F(\cdot)$.

The probability $p_{s}$ of an individual of type $s$ remaining in the public sector from period $t$ to $t+1$ is thus time-invariant and equal to

$$
p_{s}=F\left(\tilde{w}+\gamma_{s} V\left(e_{s}^{*}\right)-C\left(e_{s}^{*}\right)\right) \text {, }
$$

with $p_{l}<p_{r}<p_{m}$. The probability that a type-s worker is observed in the public sector after $t$ periods, $P_{s}(t)$, is given by

$$
P_{s}(t)=\left[F\left(\tilde{w}+\gamma_{s} V\left(e_{s}^{*}\right)-C\left(e_{s}^{*}\right)\right)\right]^{t} .
$$

\footnotetext{
${ }^{5}$ Stinebrickner (2002) for example shows that among female teachers age 32 or younger, exits to nonemployment are more common that occupation changes.
} 
Among public sector workers with $t$ years of experience, the share of workers of type $s$ is

$$
R_{s}(t)=\frac{P_{s}(t)}{P_{m}(t)+P_{r}(t)+P_{l}(t)} .
$$

An empirically testable result is that the relationship between motivation and observed effort becomes more positive with experience. Let $m(t)$ denote the probability that a worker with $t$ years of experience is of type $m$ conditional on the worker exerting effort $e_{H}$ :

$$
m(t)=\frac{R_{m}(t)}{R_{m}(t)+R_{l}(t)} .
$$

Note that initially $m(0)=0.5$, but the share of motivated workers increases over time: $m^{\prime}(t)>0 .^{6}$

The average motivation of workers with $t$ years of experience who exert high effort is $\bar{\gamma}_{e_{H}}(t)=m(t) \gamma$, while the average motivation of low-effort workers is $\bar{\gamma}_{e_{r}^{*}}(t)=0$. The model predicts that high levels of effort become more positively related to intrinsic motivation as experience increases: $d\left(\bar{\gamma}_{e_{H}}(t)-\bar{\gamma}_{e_{r}^{*}}(t)\right) / d t>0$ since $m^{\prime}(t)>0$.

The probability that a worker with $t$ years of experience who exerts effort $e_{H}$ remains in the public sector for another year is

$$
\tau(t)=m(t) p_{m}+(1-m(t)) p_{l} .
$$

It holds that high levels of effort become more strongly predictive of remaining in the public sector as experience increases: $\tau^{\prime}(t)>0$. It is straightforward to show this result since $m^{\prime}(t)>0$ and $p_{l}<p_{m}$.

The theoretical setup also implies that increasing the wage offered in the public sector

\footnotetext{
${ }^{6}$ See Appendix A for proof.
} 
can decrease average worker motivation conditional on experience. Since $\partial p_{s} / \partial \tilde{w}=f(\tilde{w}+$ $\left.\gamma_{s} V\left(e_{s}^{*}\right)-C\left(e_{s}^{*}\right)\right)$, where $f(\cdot)$ is the probability density function associated with $F(\cdot)$, it will hold under a wide range of reasonable assumptions that $0<\frac{\partial p_{m}}{\partial \tilde{w}}<\frac{\partial p_{r}}{\partial \tilde{w}}<\frac{\partial p_{l}}{\partial \tilde{w}}$, and thus $\frac{\partial R_{m}(t)}{\partial \tilde{w}}<0$. This is consistent with previous studies that have linked lower wages in the public sector to self-selection of more motivated workers (Heyes 2005, Brekke and Nyborg 2010, Rebitzer and Taylor 2011). In a review of the literature, Hanushek and Rivkin (2006) point out the lack of evidence that across-the-board salary increases lead to better student achievement. According to the model, offering higher wages does, however, increase the probability of staying in the public sector, which can have important policy implications if employers seek to reduce turnover.

Even if wages in the public sector do not depend on effort $(\partial \tilde{w} / \partial e=0)$, it is plausible that some employers offer certain nonmonetary rewards for high effort. In the case of public school teachers, I explore empirically in Section 5.4 the possibility that long hours can lead to better school assignment ${ }^{7}$ or improvement along other dimensions of the work environment. It is fairly simple to incorporate nonmonetary rewards into the model.

Suppose that nonmonetary rewards for effort (e.g. better school assignment) enter the match-specific utility function of worker $i$ working under employer $j$ as a nondecreasing function of effort for employers of type $j=1$. The model introduced above remains unchanged for employers of type $j=0$, where the prior results still hold. For example, we can think of the possibility of better school assignment as a stronger incentive for teachers at low-resource schools (type $j=1$ ) than for teachers at high-resource schools $(j=0)$. Alternatively, some principals may reward effort with better future class assignments, whereas other principals choose not to or do not have the opportunity to do so.

\footnotetext{
${ }^{7}$ There is substantial literature demonstrating that many effective teachers move to higher-resource schools; see for example Hanushek et al. (2004), who show that student body characteristics are more important than salary for teacher mobility.
} 
The modified utility function takes the form:

$$
U_{i j}(e)= \begin{cases}\tilde{w}+\gamma_{i} V(e)-C(e) & \text { for } j=0 \\ \tilde{w}+\gamma_{i} V(e)-C(e)+W_{i}(e) & \text { for } j=1\end{cases}
$$

where $W_{i}^{\prime}(\cdot) \geq 0$ and $W_{i}^{\prime \prime}(\cdot) \leq 0$. It is possible to allow for nonmonetary rewards to be used as a substitute for salary compensation by assuming different wages by employer type so that $\tilde{w}_{0}>\tilde{w}_{1}$, but this assumption is not necessary for the model. Alternatively, school districts where salaries are higher may also have more opportunities to offer other rewards for effort, in which case $\tilde{w}_{0}<\tilde{w}_{1}$. The utility function allows for the possibility that the utility derived from nonmonetary rewards differs across types. For example, intrinsically motivated teachers may derive less utility from the prospect of better school assignment, in which case $W_{m}^{\prime}(e)<W_{r}^{\prime}(e)=W_{l}^{\prime}(e)$.

Assuming that $C^{\prime}\left(e_{H}\right)=W^{\prime}\left(e_{H}\right)$, it would be the case that with employers of type $j=1$, types $r$ and $l$ both exert high effort $e_{H}$, driven to do so by the nonmonetary rewards. Type $m$ exerts effort $e_{m 1}^{*}>e_{H}$ if $W_{m}^{\prime}(e)>0$ so we would still see positive association between motivation and effort. Under reasonable assumptions for the shape of the distribution function $F(\cdot)$ and the functions $V(e)$ and $W_{i}(e)$, we would also see, conditional on experience, a higher share of motivated workers in jobs that do not offer additional rewards for effort: $R_{m 0}(t)>R_{m 1}(t)$. Empirically, I provide evidence in Section 5.4 that longer hours may be associated with transfer to higher-resource schools or other favorable characteristics of the work environment.

The model in this section can be reconciled with recent evidence that teachers who exit the profession at low levels of experience tend to have higher ability than teachers who exit later on, as measured by SAT scores and non-teaching wages (Wiswall 2007) or teacher fixed effects (Wiswall 2013). A simple modification of the model can allow for the distribution of 
outside options $F(\cdot)$ to depend on ability so that high-ability workers tend to receive better offers: $F_{r}(V)=F_{m}(V)<F_{l}(V)$ for all $V$. Under reasonable assumptions on the parameters, it would hold that $p_{r}<p_{l}<p_{m}$. Then the average ability of workers who leave the public sectors with $t$ years of experience is

$$
\bar{a}(t)=R_{m}(t)\left(1-p_{m}\right) a_{m}+R_{r}(t)\left(1-p_{r}\right) a_{r}+\left(1-R_{m}(t)-R_{r}(t)\right)\left(1-p_{l}\right) a_{l} .
$$

Denoting $a_{m}=a_{r} \equiv a_{h}$, a sufficient condition for $\bar{a}^{\prime}(t)<0$ is $\left(1-p_{m}\right) a_{h}<\left(1-p_{l}\right) a_{l} .^{8}$ Intuitively, this means that high-ability low-motivation employees are the first to leave the public sector. High-ability high-motivation workers, on the other hand, are relatively unlikely to be observed in the sample of leavers at any point. Because the slope of $\bar{a}$ with respect to experience does not depend on the initial shares of workers of each type, the result would still hold if individuals with high ability but low intrinsic motivation were relatively less likely to start off in the public sector.

The assumption of only 3 types of workers in the population simplifies the analysis and the interpretation of the results but is not necessary for the main theoretical predictions. Figure 1 shows simulation results from a similar model with continuous worker types, where $\gamma_{i}$ and $a_{i}$ are independent random draws from continuous distributions. ${ }^{9}$ Panel (a) shows that the correlation between motivation and effort increases with experience. The plot in Panel (b) illustrates the result that the hazard of leaving the public sector decreases faster over time for workers who exert high levels of effort.

In summary, the two main empirically testable predictions of the model are:

I. The correlation between motivation and effort becomes more positive with public sector

\footnotetext{
${ }^{8}$ AppendixA offers a proof.

${ }^{9}$ Specifically, $\gamma \sim U[0,1]$ and $a \sim U[1,2]$. Other parameter values are as follows: $N=100,000$ workers; $t=20$ periods; $\bar{q}=0.55 ; \tilde{w}=0.6 ; \bar{V} \sim N(0,0.5)$. The utility function takes the form $U_{i}(e)=\tilde{w}+\gamma_{i} e-e^{2}$. The results are not contingent on the shape of the uniform distribution and can be obtained with other distribution functions.
} 
experience.

II. The probability that a worker who exerts high effort remains in the public sector, compared to the probability that a low-effort worker stays, increases with experience.

These implications are contingent on the assumption that earnings do not increase with effort, and are thus most likely to apply to certain public sector jobs. This paper focuses on public school teachers. Another important feature of the model is that there are two types of workers who exert high effort for different reasons: motivated workers choose to exert high effort because they are intrinsically motivated, while low-productivity workers need to exert high effort in order to meet a production quota. This characteristic of the model leads to a dynamically evolving relationship between motivation and effort due to an underlying selection process. This conceptual framework complements prior studies such as Gregg et al. (2011), which have shown a positive relationship between public sector employment and the probability of supplying uncompensated effort (working hours), and Wiswall (2013), who examines sorting over time out of teaching based on ability. It should be noted that while heterogeneity in the level of intrinsic motivation is key in this setup, the main results in this section can also be obtained from a model with worker heterogeneity only in terms of $\gamma$ but where ability is an increasing function of experience.

In the rest of the paper I provide empirical evidence in support of the model in the context of the labor market for public school teachers. I use working hours as a measure of effort and begin by verifying that unlike most other professional occupations, particularly ones concentrated in the private sector, the earnings of teachers are almost completely flat with respect to hours. I then examine how the relationships between working hours and motivation and between the probability of remaining in teaching and hours vary with experience. 


\section{Elasticity of Teachers' Earnings with Respect to Hours}

\section{Worked}

I begin by presenting further evidence in support of the assumption that earnings for teachers are largely uncorrelated with hours. Podgursky (2011) offers a detailed overview of teacher compensation systems in the U.S., noting that salary systems are based on experience and education, with unions playing a big part. He argues that while merit and performance pay have become more common in recent years, they still do not make considerable difference in overall pay.

I use data from the 1980, 1990, and 2000 Census and from the 2001-2017 installments of the American Community Survey (ACS) provided in Ruggles, Flood, Goeken, Grover, Meyer, Pacas and Sobek (2018) to compare teachers to full-time workers in other professional occupations. Table 1 shows average working hours and their evolution over time for nine groups of occupations that are based on the 2010 SOC system. I limit the sample to workers with a Bachelor's degree between the ages of 22 and 61 who report usual weekly hours of 35 or more and who worked 27 or more weeks during the year preceding their interview. ${ }^{10}$ Because the survey asks respondents to report their usual hours in the weeks when they worked, it is likely that for teachers the measure of weekly hours reflects labor supply during the school year.

As Table 1 shows, teachers worked on average 41.5 hours in 1980, comparable to fulltime workers in computer-related and mathematical occupations and less than an hour below

\footnotetext{
${ }^{10}$ The usual definition of full-time full-year workers used in the literature, which places more conservative restrictions on the number of weeks worked, would exclude many teachers from the sample if they do not work during the summer months. Starting in 2008, the ACS provides only interval data on weeks worked. I include the 27-39 week category since the typical school year is 36 weeks in most states. There are relatively few workers in non-teaching professional occupations who report working between 27 and 39 weeks: the fraction ranges between 2 and $4 \%$ depending on the survey year. Excluding these workers does not affect the estimates for non-teaching occupations.
} 
those in business and financial occupations, as well as scientists or architects and engineers. Average hours increased for all occupations between 1980 and 1990 and for all but one occupation groups between 1990 and 2000. Hours remained fairly constant or decreased between 2000 and 2011 for all occupations with the exception of teachers. The most recent period, between 2012 and 2017, is characterized by more commonly implemented incentive pay for teachers, and their average hours in this period are approximately equal to or higher than average hours in all professional occupations except for managers and legal professionals.

Hours in these data are likely measured with error, and there is some evidence that teachers may overreport hours more than workers in other occupations (West 2014). In addition, teachers tend to work fewer weeks per year than other professionals. Nonetheless, Table 1 suggests that especially in more recent years, it is common for teachers to put in weekly hours in excess of the standard workweek, and in this respect their labor supply is similar to that of workers in most other professional occupations. The fact that teachers tend to work fewer weeks per year compared to other professionals is relevant for comparing hourly or weekly wages, which this paper does not do. The focus of this study is on the reasons for supplying more hours than required by contract in weeks when individuals are working.

Table 2 highlights the differences in the returns to long working hours for teachers and other professionals. Using the Census and ACS data, I estimate the elasticity of annual earnings with respect to weekly hours for each occupational group and for six different time periods using a method similar to the one in Goldin (2014). In particular, Table 2 reports the coefficient estimates for the interactions between the log of usual weekly hours and indicators for occupational group from regressions of the natural log of annual earnings. I also include controls for the natural log of weeks worked in the previous year, ${ }^{11}$ a quadratic in age, and

\footnotetext{
${ }^{11}$ For the years when only intervalled weeks are reported, I use the modal number of weeks as observed in surveys prior to 2008, when the actual number of weeks worked is observed. Thus, I use 36 weeks for the
} 
indicators for gender, race, Hispanic ethnicity, graduate degree, private sector employment, survey year, and detailed occupation.

There is considerable variation seen in Table 2 in the estimated elasticity of earnings with respect to hours across occupational groups. The elasticities tend to increase over time but are always lowest for teachers. ${ }^{12}$ Occupations in the health care sector and in community and social service also have low elasticity of earnings with respect to hours; Gicheva (2019) shows that earnings in occupations with high pro-social value tend to change relatively little with hours as workers in these occupations are more likely to donate labor. Goldin (2014) points out that the high elasticity of earnings with respect to hours in business and financial occupations can likely be explained by the fact that workers in these jobs tend to be poor substitutes for one another, which makes the production function convex in hours.

The main takeaway from Table 2 is that for teachers, annual earnings do not increase much, if at all, with weekly hours. The estimated elasticities are negative for 1980 and 1990 and positive but between 0.01 and 0.03 for the period between 2000 and 2017. This is consistent with the assumption in Section 2 that wages in the public sectors are fixed and do not depend on effort once output exceeds the minimum required level. At the same time, Table 1 shows that even in the absence of strong monetary incentives to supply long hours, teachers tend to supply as much labor as other professionals. Furthermore, reported job satisfaction among teachers is high relative to other occupations (Smith 2007), which points to the importance of intrinsic motivation. These issues are examined further in the rest of the paper in the context of the theory introduced in Section 2.

interval 27-39 (42\% of observations); 40 weeks for the interval 40-47 (45\% of observations); 48 weeks for the interval 48-49 (76\% of observations); and 52 weeks for the 50-52 interval (94\% of observations).

${ }^{12}$ Cortés and Pan (2019) report similar elasticity trends by broad occupational groups, but they include preschool teachers, vocational and educational counselors, librarians, archivists, and curators in the same category as primary, secondary and special education teachers and estimate higher elasticity for this group. 


\section{Schools and Staffing Survey Data}

To test the predictions of the model in Section 2, I use the 2003-04, 2007-08 and 20112012 waves of the Schools and Staffing Survey (SASS), conducted by the National Center for Education Statistics (NCES). ${ }^{13}$ Advantages of the SASS over other data sets such as administrative records from a single state or district include that it is nationally representative, covers a fairly long time period during which many districts implemented various performance or merit pay policies, provides a wide range of information including subjective measures of teacher motivation, and records turnover.

The survey uses a stratified sampling design in which a new nationally representative sample of public and private schools is selected each year; I use the public schools in the data for my analysis. The NCES assigns a unique time-invariant identification number to each school, which makes it possible to link observations for schools surveyed multiple times; about 15 percent of public schools in the data appear in multiple waves. Teachers within each sampled school are also stratified and sampled at random. Each sampled teacher is asked to complete a survey questionnaire. A follow-up survey administered at the beginning of the following academic year collects information from the school's principal on whether each of the teachers in the sample remained at the same school, continued teaching at another school, or left the teaching profession. I use this follow-up survey to construct an indicator for whether respondents changed occupations during the year following their survey. ${ }^{14,15}$ The

\footnotetext{
${ }^{13}$ The survey underwent a major redesign after the 2011-12 wave and was renamed to the National Teacher and Principal Survey.

${ }^{14}$ Preferably, turnover information would be collected from teachers rather than from administrators. A subset of the teachers who are SASS respondents are interviewed at the beginning of the following academic year for the Teacher Follow-Up Survey (TFS) and are asked to report their employment status. Comparing weighted teacher and principal responses from the 2005 TFS shows that principals are correct in identifying teachers who left the profession $69 \%$ of the time, but $25 \%$ of the teachers whom principals classify as leavers self-report to have moved to another school. I use principals' responses rather than information from the TFS because the TFS has considerably fewer respondents and sample selection is non-random, disproportionately sampling those who left their school.

${ }^{15} \mathrm{~A}$ small fraction of teachers are deceased (fewer than 0.1 percent) or have unknown status (less than 0.25 percent); they are excluded from the analysis.
} 
teacher questionnaire provides information on teachers' gender, race, ethnicity, education, years of teaching experience, subject and grade assignment, tenure, union membership, and earnings.

The final sample, which is limited to teachers who report full-time employment, includes 105,290 public school teachers at 20,270 unique schools. ${ }^{16}$ Combining all waves of the SASS, only 1,690 of the teachers appear as a unique observation within a school; the modal number of sampled teachers from a given school is 3 and the median is 4 , but 11 percent of schools have 10 or more teachers in the final estimation sample, accounting for 30 percent of teachers in the data.

Figure 2 shows the distribution of reported weekly hours among respondents in the sample; Panel (a) shows total weekly hours, ${ }^{17}$ while Panel (b) reports the difference between the total hours from Panel (a) and the number of hours each teacher reports to be required to work in order to receive base pay. Reported hours in the SASS are considerably higher than hours in the Census/ACS data, which several factors can explain. I restrict the SASS sample to include only individuals who self-report as regular full-time teachers, excluding part-time, substitute and itinerant (delivering instruction at more than one school) teachers, teacher aides and student teachers. Further, the Census and ACS questionnaires instruct respondents whose hours varied considerably in the 12 months preceding the interview to provide an average, which means that some teachers may adjust their response to account for the fact that they do not work during the summer months, especially if they are interviewed during the summer. In addition, the SASS survey question explicitly asks respondents to include hours worked on weekends and at home, while Census/ACS respondents may be less

\footnotetext{
${ }^{16}$ All SASS and TFS sample sizes in the paper are rounded to the nearest 10 as per NCES restricted-use data requirements.

${ }^{17}$ The exact wording of the survey question is "Including hours spent during the school day, before and after school, and on the weekends, how many hours do you spend on ALL teaching and other school-related activities during a typical FULL WEEK at THIS school?"
} 
likely to include hours worked outside of school. For example, Drago et al. (1999) report large discrepancies in time diary data between total labor supply and the amount of face time reported by teachers in their sample.

Figure 2 shows that it is very common for teachers to report working 50 or more hours per week or 10 or more hours above what their contract requires. Teachers may tend to overreport their hours in surveys like the SASS; West (2014) finds about a 3-hour difference between the length of the average school-year workweek for teachers as derived from time diary data compared to reported usual weekly hours in the CPS. But even with this level of overreporting, Figure 2 still indicates that a considerable fraction of full-time teachers work long hours. Figure 3, which summarizes average hours by years of teaching experience, shows that after the first four years in the profession when teachers tend to work the longest, average hours do not vary with experience. Teachers with five or more years of experience report working on average around 52 hours per week.

Table 3 shows unweighted descriptive statistics at the teacher level for the variables used in the analysis. The SASS reports detailed earnings information, including base salary, other earnings from teaching including bonuses and state supplements, non-teaching schoolrelated earnings during the school year and the summer, and earnings from other jobs. For my analysis I focus on teaching-related earnings accumulated during the school year; as Table 3 shows, the difference between base and total pay is about $\$ 1,700$, or 3.5 percent of the average base salary. This provides some evidence of the limited role of incentive pay in teaching. The table also shows that based on the principals' followup interviews, 93 percent of respondents remain in teaching one year after their survey.

I construct a subjective measure of teachers' intrinsic motivation by combining several survey questions about respondents' attitudes. The "teacher motivation" index is comprised of responses to the following survey questions. First, respondents are asked to identify on 
a 5-point Likert scale the degree to which they agree with the statement: "If you could go back to your college days and start over again, would you become a teacher or not?" Second, respondents are asked how long they plan to remain in teaching, and I construct a binary variable equal to 1 for those who selected "As long as I am able." 18 The index of teacher motivation also includes responses on a 4-point Likert scale to the statements "I don't seem to have as much enthusiasm now as I did when I began teaching" and "If I could get a higher paying job I'd leave teaching as soon as possible." I transform the variables so that higher numbers correspond to greater satisfaction with teaching and use principal component analysis to combine the four measures into a single index of teacher motivation, ${ }^{19}$ which I standardize to have mean 0 and standard deviation of 1 for all full-time teachers interviewed in the SASS, including those with missing values on some key variables.

Another subjective measure used in the analysis is meant to be indicative of burnout. Specifically, I use the degree to which respondents agree with the statement "I think about staying home from school because I'm just too tired to go." I construct an indicator variable equal to 1 if a teacher strongly disagrees with this statement and to 0 if the teacher strongly agrees, somewhat agrees or somewhat disagrees with this statement. As Table 3 shows, 53 percent of teachers disagree strongly that they feel too tired for school.

Table 3 also shows that slightly over two thirds of teachers in the sample are female, and most are white non-Hispanic. While 88 percent teach at least one Individualized Education Program (IEP) student, 43 percent have 10 or more IEP students in their classes. Union membership is common: $71 \%$ report being members of a teacher's union or similar employee association. The average age of teachers in the sample is 42 years, and respondents have 14 years of teaching experience on average. The mean tenure at the current school is close to

\footnotetext{
${ }^{18}$ Other possible responses include "Until I am eligible for retirement benefits from this job," "Until a specific life event occurs (e.g., parenthood, marriage)," "Until a more desirable job opportunity comes along," and "Definitely plan to leave as soon as I can."

${ }^{19}$ The factor loadings are shown in Appendix B.
} 
8 years. It is common for teachers to undertake additional responsibilities such as coaching a sport (21\%), sponsoring student organizations (43\%), serving as department lead or chair $(25 \%)$ or lead curriculum specialist $(11 \%)$, or serving on a district-wide committee $(50 \%)$. Over two-thirds of teachers in the sample engage in departmentalized instruction, teaching one or more subjects to multiple classes of students; these teachers have on average 2.75 different grade-subject assignments. Slightly over half of the teachers in the sample teach high school level classes, with the rest of the sample evenly split between elementary and middle school grades.

The empirical models I estimate also include indicators for highest degree earned. About half of the teachers in the SASS sample hold a graduate degree. As another measure of teacher preparation, I use the number of undergraduate and graduate courses focusing solely on teaching methods or teaching strategies that respondents have taken; this information is reported in the SASS in interval form. Table 3 shows that there is considerable variation in responses, with 9 percent of teachers in the sample having taken no teaching methods courses, and $13 \%$ reporting 1 or 2 courses. The rest of the sample is roughly evenly split among the following intervals: 3 or $4 ; 5$ to $9 ; 10$ or more.

Using the SASS sample described in Table 3, in the following section I test the predictions of the theory in Section 2 about the relationship between hours and motivation or hours and occupational changes for teachers at different levels of experience. Before doing so, I examine factors that are related to variation in hours worked and in analysis that supplements Section 3, I show evidence that the earnings of teachers in the SASS change little with hours worked. 


\section{Empirical Specifications and Results}

\subsection{Factors Related to Variations in Hours}

Before examining the outcomes of interest related to working hours for public school teachers, I explore what teacher and workplace characteristics explain some of the variation in labor supply observed in the SASS. Table 4 shows coefficient estimates from descriptive regressions of weekly hours on a series of covariates. The dependent variable in the first two specifications shown in the table is the hours required to receive base pay, while the dependent variable in columns 3 and 4 is total reported hours spent on teaching-related activities. The specifications in columns 2 and 4 include school fixed effects, while the other two models include school-level covariates.

There should not be much variation in reported contract hours, especially if school fixed effects are included in the model, and this is consistent with the estimates from the first two columns. Union membership is associated with slightly fewer contract hours. Involvement in extracurricular activities increases base hours by 0.2 per week or less, which is also a small difference. Most of the other coefficients in these specifications are not statistically significant, and those that are statistically significant are small in magnitude.

A different picture emerges from the estimates in the last two columns of Table 4 of factors related to variations in total hours; here, most covariates are highly significant, pointing to systematic labor supply differences associated with teacher and workplace characteristics. Union membership is associated with longer workweeks, as is teaching IEP students. In-

volvement in extracurricular activities is associated with an average increase of somewhere between 0.76 and 2.9 hours per week, depending on the activity. Hours tend to increase with the highest grade taught, but also elementary homeroom teachers work longer than their subject specialist coworkers. Teachers in writing-intensive subjects (English and social 
sciences) tend to work more, and so do math and science teachers. Some of these trends may be associated with teaching Advanced Placement classes, but the SASS does not collect such information so this cannot be verified. Teaching a larger number of different gradesubject combinations is also associated with higher weekly hours. Hours also increase with the number of courses in teaching methods that an individual has completed; it could be argued that more motivated teachers invest more in profession-specific human capital, but this claim cannot be verified either. The results in columns 3 and 4 are similar to each other, suggesting that within- and across-school variations in weekly hours may be driven by comparable factors.

\subsection{Do Earnings Increase with Hours for Teachers in the SASS?}

I proceed by verifying that the finding from Section 3 that teachers' earnings are only weakly related to reported weekly hours holds in the SASS sample. I estimate the year-specific elasticity of total annual teaching-related earnings with respect to reported weekly hours using an approach similar to the one in Section 3. Further, I estimate the relationship between total annual earnings or a teacher's base salary on the one hand and contract hours and hours above those required for base pay on the other. The estimation results shown in Table 5 are from models that are richer than the ones based on Census and ACS data. The specifications include the teacher-level variables in Table 3, as well as indicators for subjects taught, quadratics in teaching experience and tenure, and indicators for the first three years of tenure and experience. The regressions also include controls for school-level covariates: school level and size, the student-to-teacher ratio, the fraction of minority students and teachers at the school, the share of students who qualify for free or reduced-price lunch, an indicator for charter school, and state dummies. ${ }^{20}$ The reported errors are clustered at the

\footnotetext{
${ }^{20}$ The results are very similar if the school-level controls are replaced with school fixed effects.
} 
district level.

Column 1 of Table 5 shows very similar elasticity of annual earnings with respect to usual weekly hours for teachers to that observed in Table 2. The estimated elasticity is around 0.02 in the 2003 and 2011 surveys and 0.01 in 2007, which is again indicative of low responsiveness of earnings to an increase in hours worked compared to most other professional occupations. Columns 2 and 3 of Table 5 show results when reported hours are split between those required by contract and any hours above that. Hours enter these models linearly because some teachers report working no hours above those required to receive base pay. The estimates in column 2 suggest that there is no statistically significant relationship between the hours required for base pay and total annual compensation, but teachers who work more additional hours tend to earn slightly more: 10 additional hours per week correspond to a salary increase of 0.4 percent. This is consistent with the finding of positive but small elasticity of earnings with respect to hours. The estimated coefficients on base and additional hours are negative but also small in magnitude in column 3, where the dependent variable is the natural log of base salary. One possible explanation is that some lower-resource schools may pay less and also be understaffed so teachers need to work longer hours, and at the same time teachers with lower salaries may work more additional hours in order to increase their earnings.

Among other covariates, the models in Table 5 control for involvement in common extracurricular activities, which Table 4 shows are associated with longer hours. The results in columns 1 and 2 show that teachers get some compensation for coaching a sport (about $4 \%$ of their salary), serving as lead curriculum specialist (about 1\% salary increase), being on a district-wide committee (0.7\% salary increase), or serving as department lead or chair $(0.4 \%$ higher salary). Excluding these variables from the models results in slightly higher elasticity of earnings with respect to hours. The negative coefficients in column 3 , on the other hand, suggest that some teachers may take on extra duties, for example coaching sports or 
sponsoring student organizations, to compensate for lower base salaries.

\subsection{Labor Supply, Teacher Motivation, and Occupational Changes}

Having established the low monetary payoff to long working hours for teachers, I next use the SASS data to investigate empirically the predictions of the model in Section 2, beginning with prediction I regarding the relationship between hours and teacher motivation. I first do so descriptively in Figure 4, Panel (a) of which plots the subjective measure of teacher motivation against reported total weekly hours, while Panel (b) plots the corresponding relationship between hours and the indicator for disagreement with the statement that one feels to tired for work, which is discussed in Section 4 as a measure of lack of burnout. ${ }^{21}$ I show the relationships for teachers who fall in two experience categories: more than 0 but fewer than 6 years of teaching experience (the solid lines in Figure 4) and 21 or more years of teaching experience (the dashed lines in Figure 4). These intervals are chosen to exclude teachers who are brand new to the profession; 5 and 21 years of experience correspond to the $25^{\text {th }}$ and $75^{\text {th }}$ percentiles of the distribution. The curves and $95 \%$ confidence intervals shown in Figure 4 are from local polynomial regressions.

Panel (a) shows that the relationship between motivation and labor supply is almost flat for teachers with low levels of experience, while this relationship is considerably more positive for experienced teachers. As seen in Panel (b), burnout rates tend to increase with hours for novice teachers working more than 45 hours per week, while among experienced teachers, those working fewer hours are more likely to report being too tired for work. The trends are consistent with the theoretical framework in Section 2, which predicts that high effort

\footnotetext{
${ }^{21}$ The graphs show the relationship between hours and the residuals from regressions of the constructed motivation index or burnout measure on indicators for grades and subjects taught, a quadratic in teaching experience, indicators for survey year, and school-level controls for school type (elementary, middle or high) and size, the student-to-teacher ratio, the fraction of minority students and teachers at the school, the share of students who qualify for free or reduced-price lunch, an indicator for charter school, and state dummies.
} 
becomes more indicative of intrinsic motivation in the public sector as experience increases.

To explore the relationships further, I estimate models in which the dependent variables are the measures of commitment to teaching used in Figure 4: the teacher motivation index and the measure of burnout. To test prediction II of the model, I also estimate models in which the dependent variable is an indicator variable that equals 1 for individuals who continued working as teachers in the year following their interview, either at their current or a different school, and 0 for those who left the profession. In the case of the two binary dependent variables, I estimate linear probability models, which have the advantage of easily interpretable coefficients, particularly in the presence of school fixed effects; using other specifications such as conditional logit produces similar results, which are available on request. I estimate the following model for teacher $i$ at school $j$ :

$$
y_{i j}=\alpha_{j}+\gamma_{1} h_{i j}+\gamma_{2} h_{i j} T_{i}+\mathbf{X}_{i j} \beta+\varepsilon_{i j}
$$

where $h_{i j}$ denotes reported weekly hours, ${ }^{22}$ and $T_{i}$ is individual $i$ 's experience as teacher, measured in years. The variable $T$ measures actual experience; respondents are instructed to exclude periods spent on parental leave or sabbatical when reporting the number of years of teaching experience they have accumulated.

The model in (3) assumes away systematic cohort-specific differences in teacher motivation or turnover rates. Because the analysis is based on three waves of data, and because $T$ measures potential experience and is not perfectly collinear with cohort even in a cross section of the data, it is possible to identify cohort effects separately from the coefficients on experience. However, there is no evidence that motivation varies in a systematic way by cohort and the latter needs to be included in the model. Appendix $\mathrm{C}$ shows that once

\footnotetext{
${ }^{22}$ I estimate models with total weekly hours as a right-hand side variable; using hours required for base pay and additional hours, with the latter interacted with experience, produces similar results.
} 
experience is accounted for, the values of the motivation index do not vary by the year when teachers entered the profession past 1970, which constitutes over $99 \%$ of the sample. Furthermore, the results do not change if cohort fixed effects are added to the model; these alternative estimates are available on request.

The additional controls in $\mathbf{X}_{i j}$ include indicators for gender, race and Hispanic ethnicity; quadratics in age, experience as teacher, and tenure at the current school; indicators for each of the first three years of experience and tenure; indicators for graduate degree and for the number of courses in teaching methods taken by a respondent; indicators for union membership, subjects and highest grade taught, and for whether the respondent teaches any students with an Individualized Education Program (IEP) and another indicator for 10 or more IEP students; the number of different subject-grade teaching assignments; and indicators for survey year. I also include school-specific intercepts $\alpha_{j}$. The errors are clustered at the district level. In some specifications I also include controls for extracurricular activities, which Tables 4 and 5 show to be related to both hours worked and salary. However, if involvement in extracurricular activities is partly driven by intrinsic motivation, their inclusion in the model could pick up part of the effect of motivation on hours, weakening the underlying relationships of interest. Thus, I show results with these variables but exclude them from the main specifications. I also control in all regressions for the natural log of teacher $i$ 's total teaching-related annual earnings, which should capture the extrinsic rewards to taking on additional duties.

Table 6 shows estimation results for the model in (3) where the dependent variable is the teacher motivation index (columns 1 through 5) or the binary indicator equal to 1 if a teacher strongly disagrees that she feels too tired for school (column 6). Columns 1 and 6 show the main estimates based on the model in (3); the school fixed effects are replaced with detailed school-level characteristics in column 2. Column 3 shows results with controls for 
extracurricular activities. Teachers with fewer than 3 years of experience are excluded from the sample in column 4. An argument can be made that it takes time for teachers to adjust their labor supply to the demands of the profession, and it also takes time for an individual to decide whether teaching is the right occupation. The sample in column 5 excludes female teachers under the age of 34 . It is common for young female teachers to leave the profession temporarily to take care of young children; Stinebrickner (2002) shows the presence of a newborn child to be the strongest predictor of leaving the profession for female teachers in his sample from the National Longitudinal Study of the High School Class of 1972, where the oldest respondents are around 32 years old. Dolton and van der Klaauw (1999) also find family reasons to be an important factor. Family-related reasons can be thought of as an outside option within the framework of the theory in Section 2, but many females may eventually return to teaching, which would not be captured in the data because retention is measured only one year after the initial interview.

As predicted by the theory in Section 2, the estimate for $\gamma_{2}$ is positive and highly statistically significant in all specifications: the measure of teacher motivation is more strongly correlated with working hours at higher levels of experience. For teachers new to the profession, long working hours are generally not predictive of motivation. For experienced teachers, long hours are positively correlated with motivation. This result is slightly more pronounced in the model with school fixed effects and becomes even stronger when novice teachers or the females most likely to have children are excluded from the sample. These finding are consistent with the selection-based framework where high-effort low-motivation employees are likely to leave the public sector relatively fast, while employees who are intrinsically motivated and derive utility from the effort they exert are likely to remain in the public sector and are more strongly represented among those with high levels of experience.

The results also show that teacher motivation is positively related to the likelihood of 
taking on additional responsibilities such as coaching a sport, sponsoring a student organization, or taking on leadership positions, as shown in column 3. Teachers' earnings are positively correlated with motivation, but it is unclear from these estimates to what extent better-paid teachers feel more motivated, as opposed to intrinsically motivated teachers being able to attain better-paying positions. The magnitude of the coefficient from the main model in column 1 implies that a salary increase from $\$ 45,000$ to $\$ 55,000$ corresponds to an increase in motivation of about 0.03 standard deviations.

The results in column 6 of Table 6 suggest that longer working hours are on average associated with burnout for novice teachers, for whom 10 additional hours per week make it 1.3 percentage points more likely to report being too tired for school. Among teachers with more than 14 years of experience, those who work longer hours are less likely to report burnout. This finding provides further support for the idea that long hours in the public sector are indicative either of intrinsic motivation or of low productivity. Total earnings are negatively related to burnout, but it is again not possible to identify the direction of causality.

Table 7 shows how the relationship between working hours and the probability of remaining in teaching changes with experience; the estimation results are from linear probability models as shown in (3) in which the dependent variable is an indicator equal to 1 if an individual was still working as teacher in the year following their initial interview. The specifications in columns 1 through 3 are similar to those in the first three columns of Table 6 ; columns 5 and 6 impose the same sample restrictions as columns 4 and 5 of Table 6 ; finally, the specification in column 4 is similar to the main model in column 1 but also includes the measures of motivation and burnout as regressors.

The estimation results in Table 7 suggest that longer hours are predictive that a teacher will remain in the profession for experienced teachers, but at low levels of experience hours 
are not strongly correlated with retention. While highly significant, the coefficient estimates for $\gamma_{2}$ are not large; the results from the main model in column 1 indicate that if we compare two teachers with 10 years of experience, the one who works 10 fewer hours is about 0.5 percentage points more likely to leave teaching over the next year: a 7 percent increase in turnover given the baseline retention rate of $93 \%$.

Figure 5 illustrates the estimated effects from column 1 at different levels of experience. The predicted probability of remaining in teaching is shown for two values of weekly hours, 40 and 55. The predicted probability of remaining in the profession has an inverse U-shape with respect to experience for both groups. The probability of leaving the profession starts off approximately the same for standard- and long-hour teachers but diverges over time, with the difference still not statistically significant at 5 years of experience but highly significant at 10 years and after that. The estimated difference in the predicted probability of leaving the profession between teachers who work 40 hours per week and those who work 55 hours per week is close to 2 percentage points at 30 years of experience.

Column 2 of Table 7 shows that the results become somewhat weaker but remain qualitatively the same when the school fixed effects are replaced with controls for school characteristics. The estimated coefficient on the interaction between hours and experience is also slightly lower but still highly statistically significant when the controls for extracurricular activities are included in the model in column 3, with participation in all included activities except for serving as lead curriculum specialist being positively correlated with retention. The measure of motivation and indicator for not suffering from burnout are also strongly positively correlated with retention, and their inclusion in the model similarly attenuates the estimate of $\gamma_{2}$, although it remains highly significant. The coefficient estimate for the interaction between hours and experience remains similar to that in the main specification when novice teachers are excluded from the sample (column 5) and becomes larger when the 
sample is restricted to exclude females younger than 34. The latter suggests that intrinsic motivation may be less of a factor in retention for young female teachers, but it is possible that exits are temporary for many members of this group. Earnings are also positively related to the probability of remaining in teaching, with a $20 \%$ salary increase being associated with a $0.2-0.3$ percentage point increase in the probability of remaining in teaching for another year.

\subsection{Other Nonmonetary Returns to Long Hours}

The findings presented so far in this section and in Section 3 are consistent with selection on intrinsic motivation in a setting where earnings do not increase with hours. As Section 2 points out, it is possible that public sector jobs have non-monetary incentives built into them that reward workers for effort, and these other incentives can also drive public sector workers to exert more than the minimum level of effort. Here I provide suggestive evidence that this may be the case for some public school teachers, although the data do not allow me to draw strong conclusions.

For example, one can consider the possibility that principals and other school administrators, who do not have much freedom to reward teachers monetarily, may use the prospect of transfer to a more desirable school as reward for high effort. To test this hypothesis, I rely on the relatively small subsample of teachers who were interviewed a year after their SASS survey as part of the Teacher Follow-Up Survey (TFS). For respondents who remained in teaching, I use information from the TFS about the ZIP codes of the schools where they worked at the time of the SASS and TFS interviews; the location would be the same for respondents who did not change schools. I then link the ZIP codes to data from the 2000 Census on mean family income in the ZIP code where each school is located. Family income is a proxy for school resources, the assumption being that schools in higher-income areas 
tend to be more desirable. Prior studies of teacher mobility such as Hanushek et al. (2004) have demonstrated that at least a subset of teachers seek to move to schools or districts serving students of higher socioeconomic status.

Columns 1 and 2 of Table 8 show coefficient estimates from a regression of mean family income in the ZIP code of the school where a teacher worked in year $t+1$ (as reported in the TFS) on mean family income for the year- $t$ school and controls for total hours, the teacher motivation index, the other variables from Table 3 including the natural log of total schoolrelated earnings, and school-level covariates. I split the sample into teachers who started off at schools in areas with higher than median family income (column 1) and those who in year $t$ worked at schools in areas with lower than median family income (column 2).

The estimates in the first two columns of Table 8 are consistent with the idea that for teachers at low-resource schools, long hours might lead to better school assignment; the coefficient on weekly hours is positive and significant in column 2, indicating that longer hours are associated with an increase in average income in the ZIP code where a teacher works. There is not a statistically significant relationship between hours and mean family income at $t+1$ for teachers whose initial school is located in a higher-income area. The results also show that motivated teachers are less likely to move from low- to higher-resource schools, which is also consistent with the theory assuming that the utility of nonmonetary rewards is lower for intrinsically motivated teachers. Teachers who have higher earnings are more likely to move to an area with higher family income, which may be driven by nonlinearities in experience or performance-related indicators that the regressions do not capture.

Columns 3 through 6 of Table 8 explore other potential nonmonetary rewards for effort, using the TFS to compare respondents' perceptions of their work environment for those who were still working as teachers at time $t+1$. The TFS asks respondents how their 
current position compares to last year's position along different dimensions. I construct indicators for whether one perceives their job in year $t+1$ to be better than the job in year $t$ in terms of opportunities for professional development, promotion opportunities, general working conditions, and manageability of the workload. Each of these indicators is used as a dependent variable in linear probability models with the same covariates as in the specifications in columns 1 and 2 of Table 8, and the results are shown in columns 3-6. Longer hours are associated with perceived improvements in working conditions for 3 of the 4 outcomes, general working conditions being the exclusion. This finding suggests that school administrators may use nonmonetary rewards to incentivize teachers to exert higher effort, although the SASS and TFS data are not well-suited to examine this possibility in greater detail.

The observed link between motivation and hours should be less pronounced if teachers who are not intrinsically motivated may be incentivized by the prospect of better future assignments to put in long hours at low-resource schools. To explore this possibility further, I re-estimate the models whose results are shown in column 1 of Tables 6 and 7 separately for teachers at low- and high-resource schools, as measured by the percent of students at the school who are approved for the National School Lunch Program (NSLP). ${ }^{23}$ The results are shown in Panel A of Table 9, where columns 1 and 3 display results for schools where less than $25 \%$ of students are approved for free or reduced lunch, while columns 2 and 4 restrict the sample to schools with more than $50 \%$ NSLP students.

The estimates in the first two columns of Panel A of Table 9 show that the result that hours are more strongly correlated with the probability of remaining in teaching at higher levels of experience is more pronounced at schools where relatively few students are ap-

\footnotetext{
${ }^{23}$ This is a more accurate measure of family resources at the school level than family income in the school's ZIP code but is not available in the TFS, which is why the specifications in Table 8 use family income in the school's ZIP code as a measure of school resources.
} 
proved for free or reduced lunch; a similar trend emerges in columns 3 and 4 regarding the relationship between motivation and hours. The coefficient estimates for the interaction between hours and experience in columns 2 and 4 are less than half as large in magnitude as the corresponding estimates in columns 1 and 3, suggesting that the model in Section 2 is less representative of the teacher labor market at low-resource schools. Table 8 shows some evidence that the reason may be that hours serve additional functions at lower-resource schools. In particular, it is possible that school administrators reward high effort with better workplace assignment when they are constrained in their use of monetary incentives; this mechanism should be explored further with better-suited data.

Panel B of Table 9 explores whether the relationship between hours and motivation or retention is heterogeneous by school level. Arguably, most high school subjects offer higher potential for donating uncompensated labor. For example, high school teachers have more discretion over how many essays or projects to assign or how much time to spend on instruction outside the regularly scheduled class time. It is plausibly also the case that less productive high school teachers need more additional time to meet the minimum required level of output than elementary school teachers. Then the model in Section 2 would be more representative of the labor market for high school teachers than for individuals who teach lower grades. Columns 1 and 3 of Panel B show estimation results for the sample of elementary and middle school teachers, while columns 2 and 4 restrict the sample to the high school teachers in the sample. ${ }^{24}$ The results show much more pronounced positive relationship between hours and retention or motivation at high levels of experience for high school teachers compared to teachers as elementary and middle schools.

\footnotetext{
${ }^{24}$ There is a small number of schools in the main sample that do not fit into these categories, offering combined grade levels. They are excluded from the samples in Table 9.
} 


\section{Conclusion}

It is somewhat of a puzzle why we observe variations in labor supply for full-time workers in occupations where the monetary rewards for long working hours are small. In this paper I propose two explanations, pro-social motivation and low productivity combined with contractually enforceable minimum output. I also suggest a way to distinguish between the two empirically in the context of the labor market for public school teachers in the U.S. This market is characterized by flat pay structure that mainly depends on experience and education, and a large fraction of workers whose reported weekly hours exceed 50 .

To formalize the main idea of the paper, I introduce a theoretical framework in which public sector employees differ in their productivity and motivation, and high effort can be indicative of either altruism or low ability. Consequently, teachers may work long hours either because they derive utility from their work, or because they need additional time to complete the required tasks. To distinguish between motivated and low-productivity teachers empirically, I use three waves of the Schools and Staffing Survey to analyze the relationship between observed weekly hours and the probability of exiting the teaching profession at different levels of experience. I also examine a similar relationship between hours and subjective measures of motivation and burnout.

The theory predicts and the data show that long hours are not necessarily predictive of intrinsic motivation or occupational changes for teachers who are new to the profession. At higher levels of occupational experience, selection leads to motivated workers being more strongly represented than low-productivity workers, and the likelihood that long hours are

driven by altruism increases. As a result, the relationship between weekly hours and the probability of exiting teaching becomes more negative with experience. Using the subjective measures of teacher motivation and burnout, I show further evidence that, as predicted by the theory, labor supply is more closely linked to motivation at higher levels of experience. 
The importance of labor supply for the careers of college-educated workers has been the focus of several recent papers such as Gicheva (2013), Goldin (2014), and Cortés and Pan (2019). The current study adds to the discussion by analyzing uncompensated long hours in the public sector. Many public sector employees, such as teachers, are not as strongly incentivized by career advancement concerns and monetary compensation as are workers in legal and financial occupations in the private sector for example, and it is important to take intrinsic motivation into account when trying to answer the question of why some, but not all, public sector employees have a tendency to donate labor. As Tables 1 and 2 show, the phenomenon of relatively long weekly hours and elasticity of earnings with respect to hours close to zero is not limited to the labor market for teachers. Health-related occupations, for example, also fit this pattern. There is further evidence that many public sector employees working in the fields of health, education and social care tend to supply additional uncompensated hours (Gregg et al. 2011), which is in line with the theoretical framework presented here. The approach in this paper can be extended further to examine to what extent the patterns apply to other occupations and other dimensions of effort, not measurable in the data used in this study. 


\section{References}

Andreoni, James, "Giving with impure altruism: Applications to charity and Ricardian equivalence," Journal of Political Economy, 1989, $9^{77}$ (6), 1447-1458.

Arens, A Katrin and Alexandre J. S. Morin, "Relations between teachers' emotional exhaustion and students' educational outcomes.," Journal of Educational Psychology, 2016, 108 (6), 800 .

Atkinson, Adele, Simon Burgess, Bronwyn Croxson, Paul Gregg, Carol Propper, Helen Slater, and Deborah Wilson, "Evaluating the impact of performance-related pay for teachers in England," Labour Economics, 2009, 16 (3), 251-261.

Besley, Timothy and Maitreesh Ghatak, "Competition and incentives with motivated agents," The American Economic Review, 2005, 95 (3), 616-636.

and __ "Sorting with motivated agents: implications for school competition and teacher incentives," Journal of the European Economic Association, 2006, 4 (2-3), 404414.

Brekke, Kjell Arne and Karine Nyborg, "Selfish bakers, caring nurses? A model of work motivation," Journal of Economic Behavior \& Organization, September 2010, 75 (3), 377-394.

Cortés, Patricia and Jessica Pan, "When Time Binds: Substitutes for Household Production, Returns to Working Long Hours, and the Skilled Gender Wage Gap," Journal of Labor Economics, April 2019, 37 (2).

Delfgaauw, Josse and Robert Dur, "Incentives and workers' motivation in the public sector," The Economic Journal, 2008, 118 (525), 171-191.

Dolton, Peter and Wilbert van der Klaauw, "Leaving teaching in the UK: A duration analysis," The Economic Journal, 1995, pp. 431-444.

and _ , "The turnover of teachers: A competing risks explanation," The Review of Economics and Statistics, 1999, 81 (3), 543-550.

Drago, Robert, Robert Caplan, David Costanza, Tanya Brubaker, Darnell Cloud, Naomi Harris, Russell Kashlan, and T Lynn Riggs, "New Estimates of Working Time for Elementary School Teachers.," Monthly Labor Review, 1999, 122 (4), 31-40.

Francois, Patrick and Michael Vlassopoulos, "Pro-social motivation and the delivery of social services," CESifo Economic Studies, 2008, 54 (1), 22-54.

Gaynor, Martin, James B Rebitzer, and Lowell J Taylor, "Physician incentives in health maintenance organizations," Journal of Political Economy, 2004, 112 (4), 915931.

Gershenson, Seth, "Performance standards and employee effort: Evidence from teacher absences," Journal of Policy Analysis and Management, 2016, 35 (3), 615-638. 
Gicheva, Dora, "Working long hours and early career outcomes in the high-end labor market," Journal of Labor Economics, 2013, 31 (4), 785-824.

_ , "Occupational Social Value and Returns to Long Hours," Economica, 2019. Forthcoming.

Goldin, Claudia, "A Grand Gender Convergence: Its Last Chapter," American Economic Review, April 2014, 104 (4), 1091-1119.

Goodman, Sarena F and Lesley J Turner, "The design of teacher incentive pay and educational outcomes: Evidence from the New York City bonus program," Journal of Labor Economics, 2013, 31 (2), 409-420.

Greenberg, Mark, Joshua L. Brown, and Rachel Abenavoli, "Teacher Stress and Health Effects on Teachers, Students, and Schools," Edna Bennett Pierce Prevention Research Center, Pennsylvania State University 2016.

Gregg, Paul, Paul A Grout, Anita Ratcliffe, Sarah Smith, and Frank Windmeijer, "How important is pro-social behaviour in the delivery of public services?," Journal of Public Economics, 2011, 95 (7), 758-766.

Hanushek, Eric A and Steven G Rivkin, "Teacher quality," Handbook of the Economics of Education, 2006, 2, 1051-1078.

, John F Kain, and Steven G Rivkin, "Why public schools lose teachers," Journal of Human Resources, 2004, 39 (2), 326-354.

Heyes, Anthony, "The economics of vocation or "why is a badly paid nurse a good nurse'?," Journal of Health Economics, 2005, 24 (3), 561-569.

Hoxby, Caroline M, "Would School Choice Change the Teaching Profession?," Journal of Human Resources, 2002, pp. 846-891.

Ingersoll, Richard M, "Teacher turnover and teacher shortages: An organizational analysis," American Educational Research Journal, 2001, 38 (3), 499-534.

Krantz-Kent, Rachel, "Teachers' work patterns: When, where, and how much do US teachers work," Monthly Labor Review, 2008, 131, 52.

Lavy, Victor, "Performance pay and teachers' effort, productivity, and grading ethics," The American Economic Review, 2009, 99 (5), 1979-2021.

Macartney, Hugh, Robert McMillan, and Uros Petronijevic, "Teacher Performance and Accountability Incentives," 2018. National Bureau of Economic Research Working Paper No. 24747.

Murnane, Richard J and Randall J Olsen, "The effect of salaries and opportunity costs on duration in teaching: Evidence from Michigan," The Review of Economics and Statistics, 1989, pp. 347-352. 
_ _ and _ _ , "The effects of salaries and opportunity costs on length of stay in teaching: Evidence from North Carolina," Journal of Human Resources, 1990, pp. 106-124.

Podgursky, Michael, Teacher Compensation and Collective Bargaining, Vol. 3 of Handbook of the Economics of Education, Elsevier, December

and Matthew G. Springer, "Credentials Versus Performance: Review of the Teacher Performance Pay Research," Peabody Journal of Education, 2007, 82 (4), 551-573.

Podgursky, Michael J and Matthew G Springer, "Teacher performance pay: A review," Journal of Policy Analysis and Management, 2007, 26 (4), 909-949.

Podgursky, Michael, Ryan Monroe, and Donald Watson, "The academic quality of public school teachers: An analysis of entry and exit behavior," Economics of Education Review, 2004, 23 (5), 507-518.

Prendergast, Canice, "The motivation and bias of bureaucrats," The American Economic Review, 2007, pp. 180-196.

Rebitzer, James B and Lowell J Taylor, "Extrinsic rewards and intrinsic motives: standard and behavioral approaches to agency and labor markets," Handbook of Labor Economics, 2011, 4, 701-772.

Ruggles, Steven, Sarah Flood, Ronald Goeken, Josiah Grover, Erin Meyer, Jose Pacas, and Matthew Sobek, IPUMS USA: Version 8.0 [dataset], Minneapolis, MN: IPUMS, 2018. https://doi.org/10.18128/D010.V8.0.

Scafidi, Benjamin, David L Sjoquist, and Todd R Stinebrickner, "Do teachers really leave for higher paying jobs in alternative occupations?," Advances in Economic Analysis \& Policy, 2005.

Smith, Tom W., "Job Satisfaction in the United States," Technical Report, NORC/University of Chicago 2007.

Stinebrickner, Todd R, "An analysis of occupational change and departure from the labor force: Evidence of the reasons that teachers leave," Journal of Human Resources, 2002, pp. 192-216.

Stoddard, Christiana and Peter Kuhn, "Incentives and effort in the public sector: Have US education reforms increased teachers' work hours?," Economics of Education Review, 2008, 27 (1), 1-13.

West, Kristine L., "New Measures of Teachers' Work Hours and Implications for Wage Comparisons," Education Finance and Policy, July 2014, 9 (3), 231-263.

Wiswall, Matthew, "Licensing and occupational sorting in the market for teachers," 2007. New York University, Department of Economics.

__ "The dynamics of teacher quality," Journal of Public Economics, 2013, 100, 61-78. 
Figure 1: Simulation of Model with Continuous Types

(a) Correlation between Motivation and Effort

(b) Probability of Staying in the Public Sector over Time

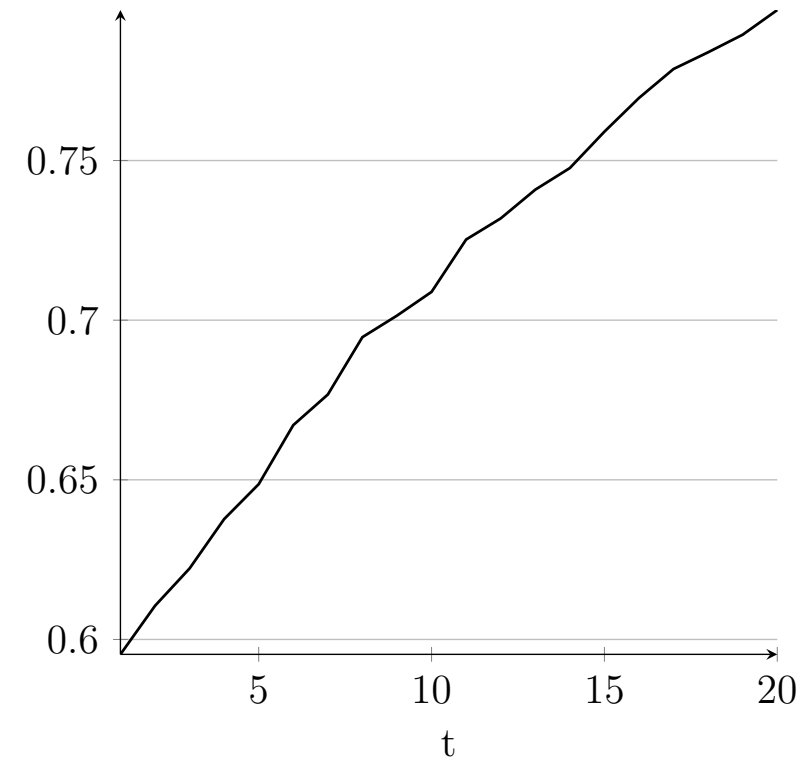
from $t$ to $t+1$ Conditional on Being in the Public Sector at $t$

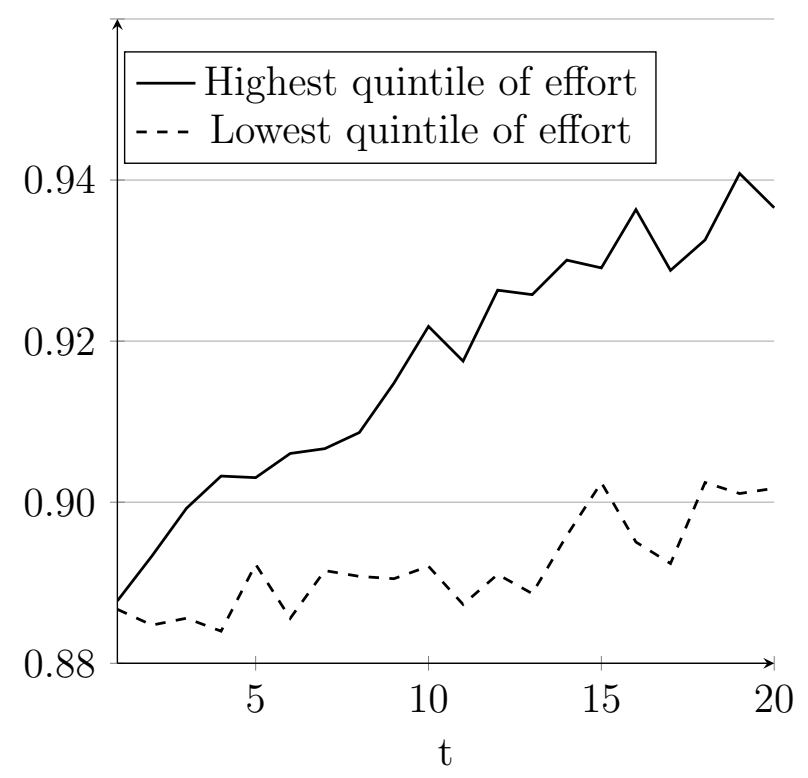

Simulation results for the model in Section 2 where $\gamma \sim U[0.1] ; a \sim U[1,2] ; N=100,000$ workers; $t=20$ periods; $\bar{q}=0.55 ; \tilde{w}=0.6 ; \bar{V} \sim N(0,0.5)$. The utility function takes the form $U_{i}(e)=\tilde{w}+\gamma_{i} e-e^{2}$.

Figure 2: Distribution of Reported Hours in the SASS

(a) Total Hours

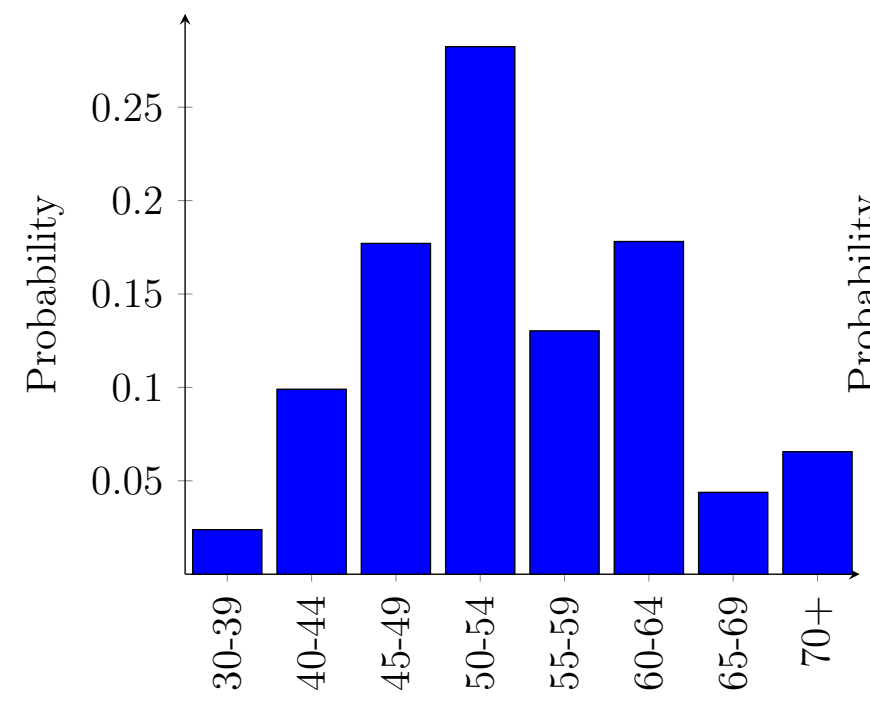

Hours (b) Hours above Contract

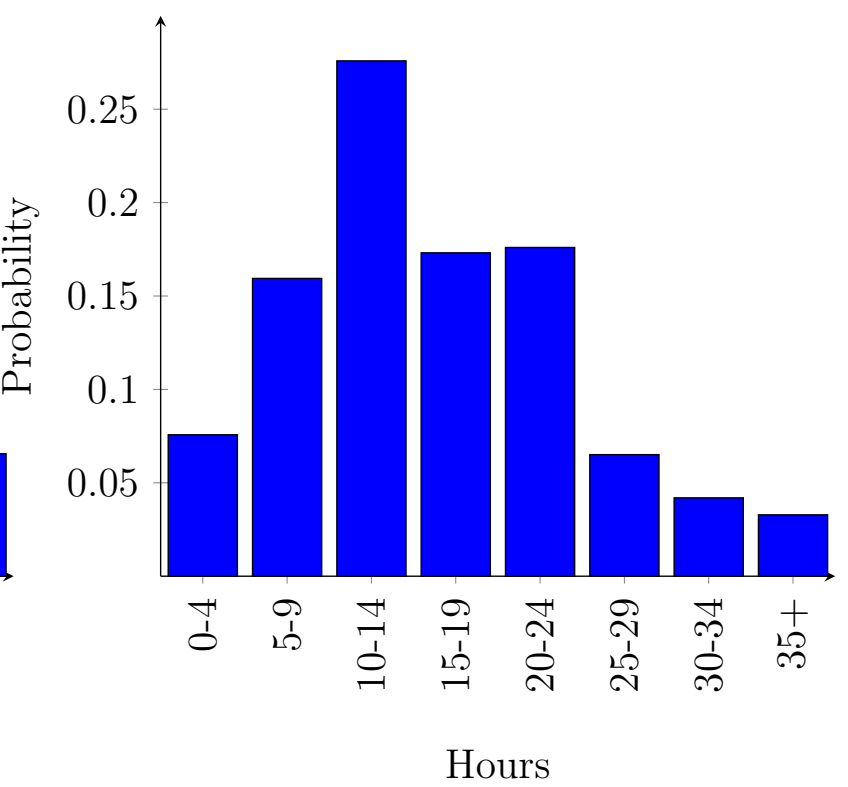

Source: U.S. Department of Education, National Center for Education Statistics, Schools and Staffing Survey, 2003-04, 2007-08, and 2011-12. 
Figure 3: Average Working Hours by Years of Teaching Experience

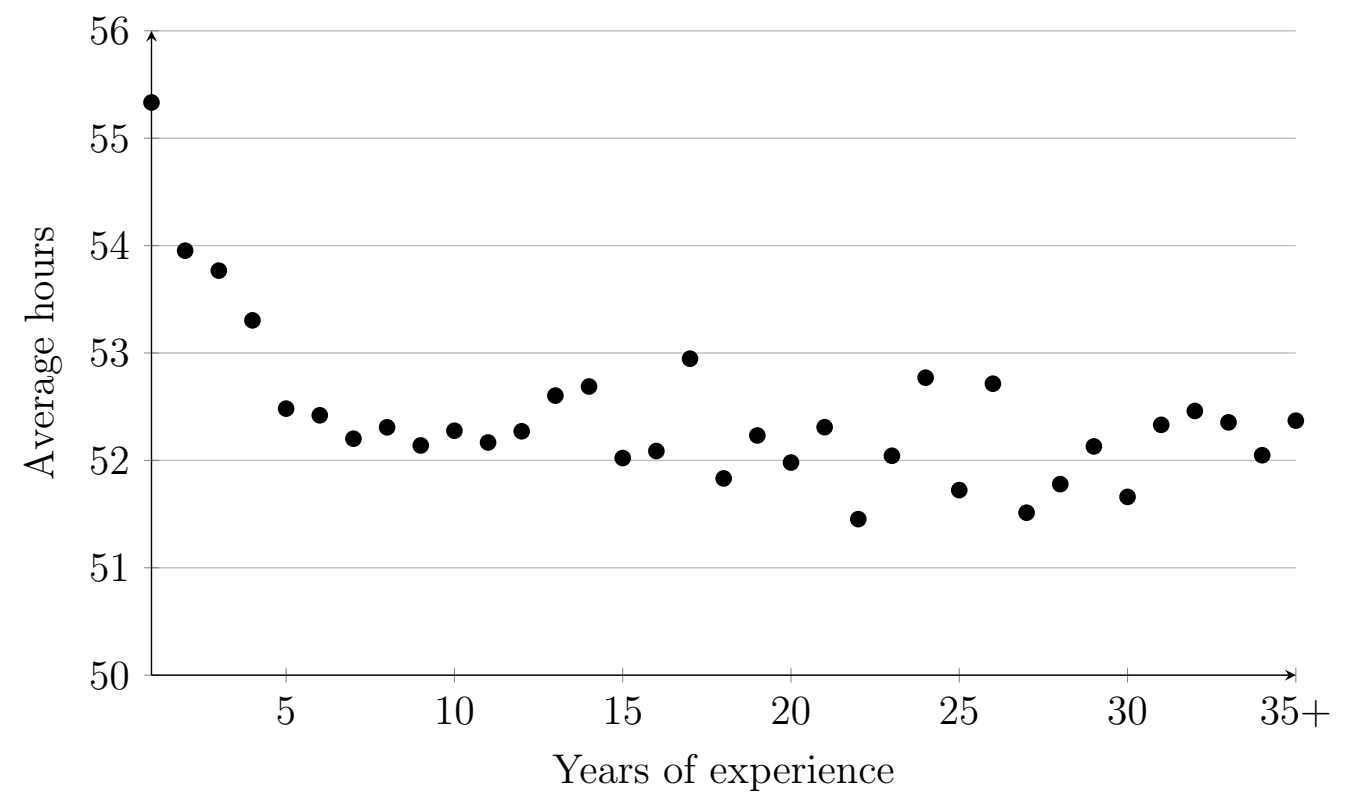

The calculations use SASS teacher weights.

Source: U.S. Department of Education, National Center for Education Statistics, Schools and Staffing Survey, 2003-04, 2007-08, and 2011-12. 
Figure 4: Relationship Between Working Hours, Motivation, and Burnout

(a) Motivation and Working Hours

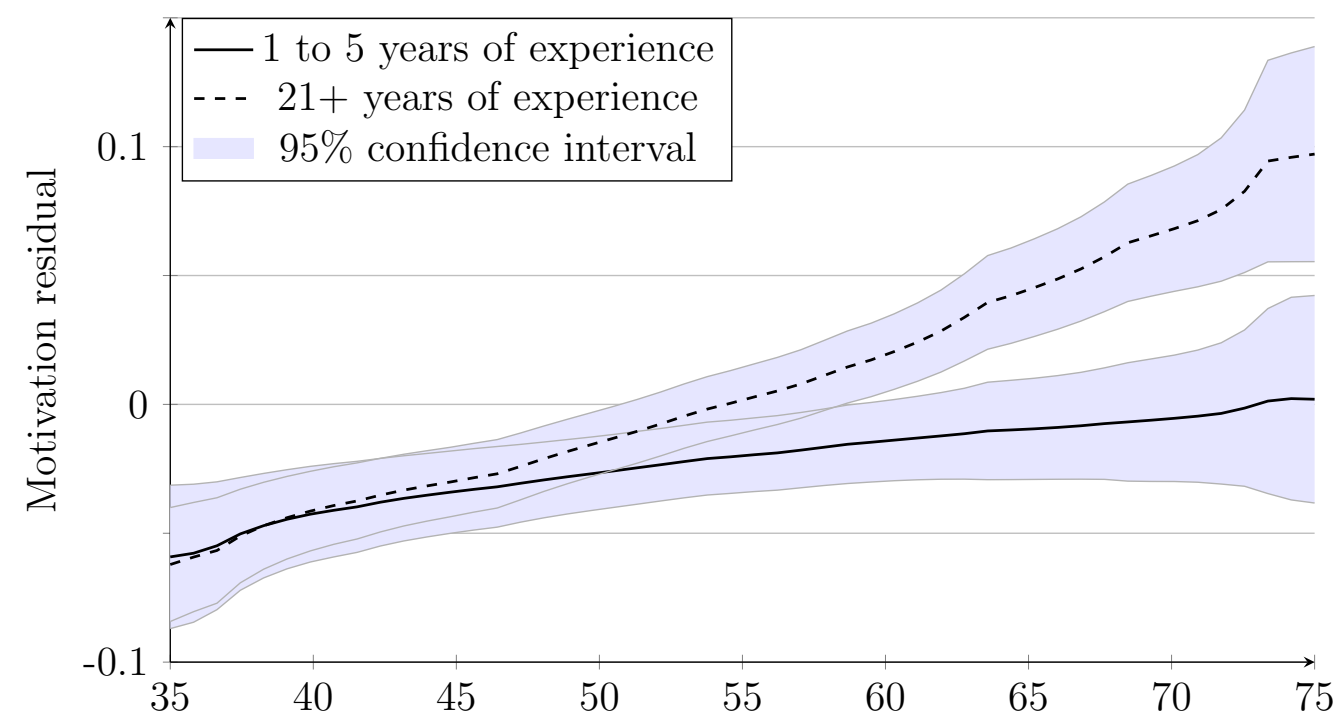

(b) Burnout and Working Hours

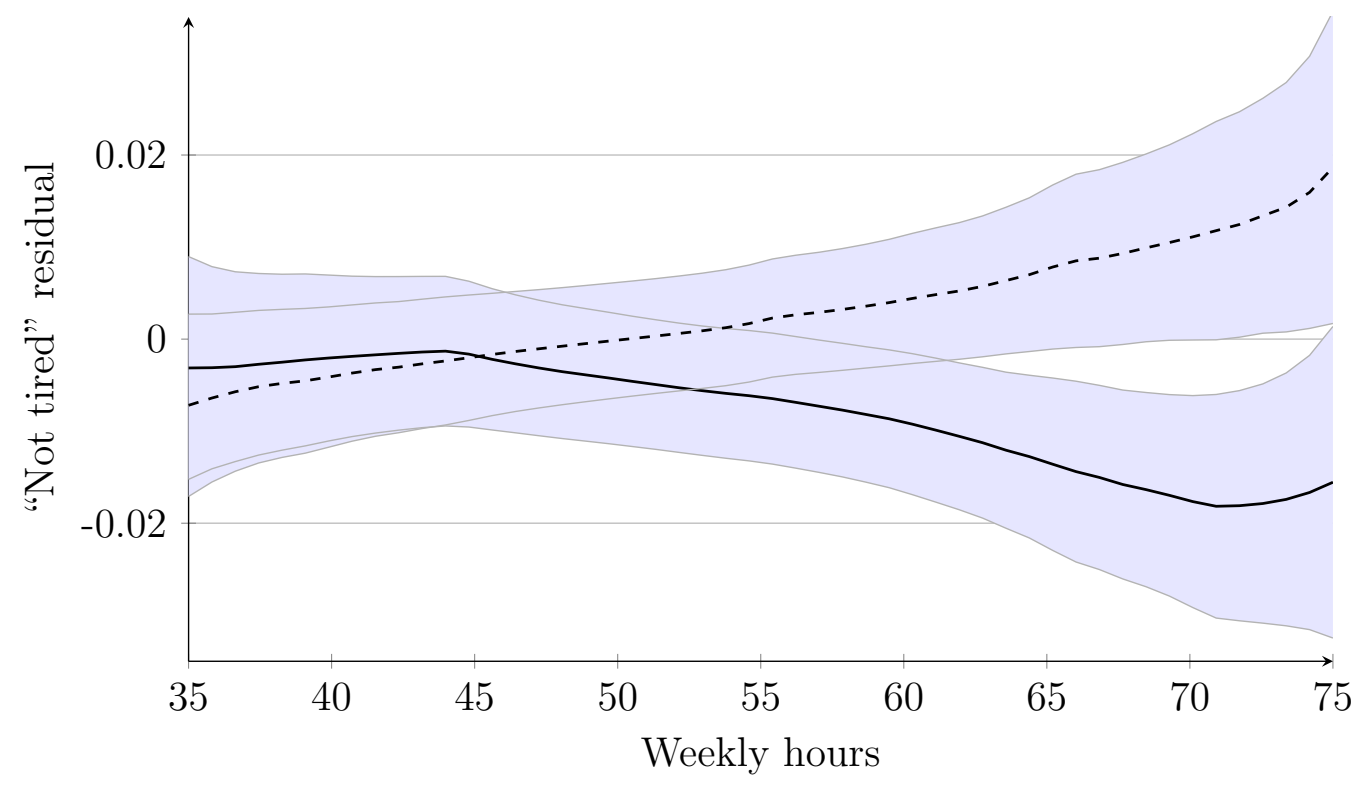

Local polynomial regression results. The residuals are obtained from regressions of the teacher motivation index described in Section 4 or an indicator for strongly disagreeing with the statement "I think about staying home from school because I'm just too tired to go" on indicators for subjects and highest grade taught, a quadratic in teaching experience, indicators for survey year, and school-level controls for school type (elementary, middle or high) and size, the student-to-teacher ratio, the fraction of minority students and teachers at the school, the share of students who qualify for free or reduced-price lunch, an indicator for charter school, and state dummies.

Source: U.S. Department of Education, National Center for Education Statistics, Schools and Staffing Survey, 2003-04, 2007-08, and 2011-12. 
Figure 5: Predicted Probability of Remaining in Teaching

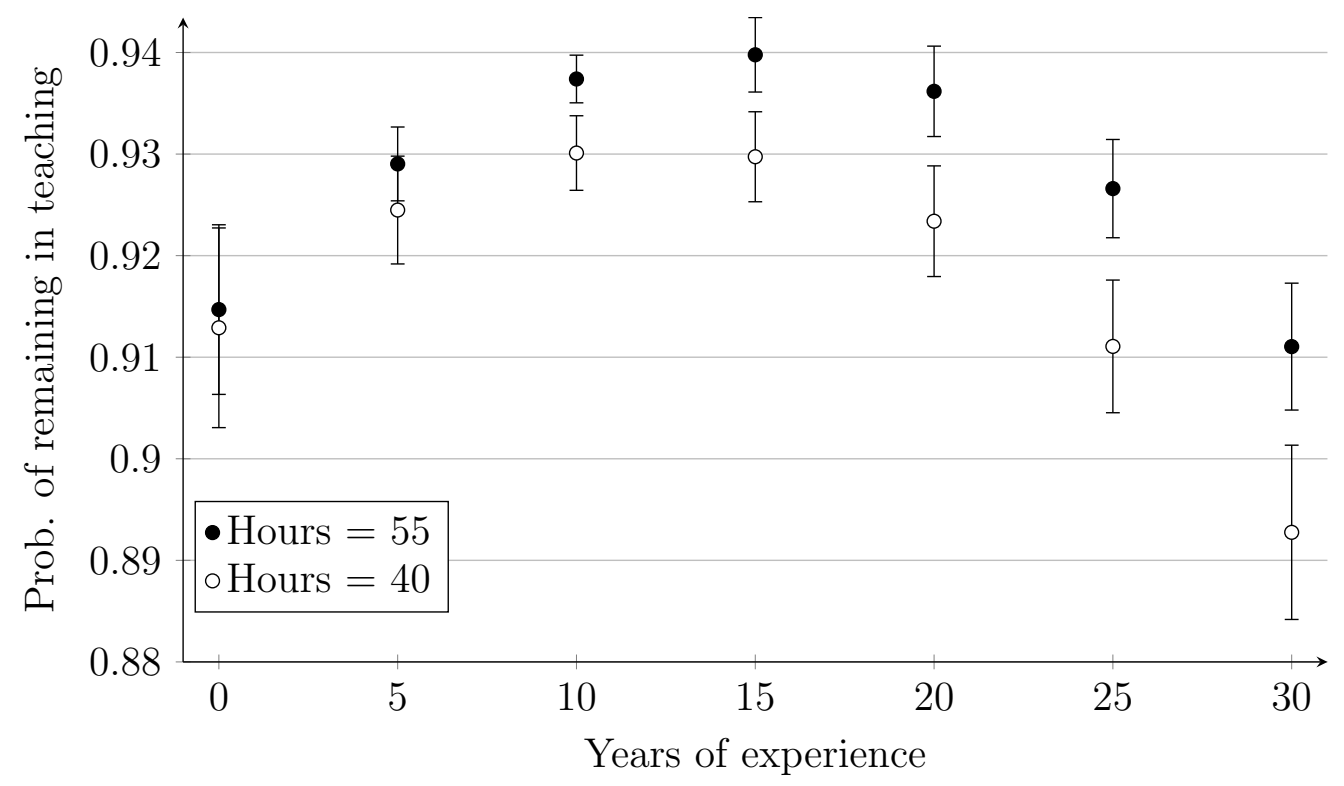

Linear prediction and 95\% confidence intervals based on the specification in column 1 of Table 7. Source: U.S. Department of Education, National Center for Education Statistics, Schools and Staffing Survey, 2003-04, 2007-08, and 2011-12. 
Table 1: Average Hours Worked per Week in Professional Occupations

\begin{tabular}{lcccccc}
\hline & 1980 & 1990 & 2000 & $2001-2005$ & $2006-2011$ & $2012-2017$ \\
\hline \hline Teachers & 41.54 & 42.50 & 43.60 & 43.62 & 43.74 & 44.22 \\
{$[2310-2330]$} & $(6.026)$ & $(6.526)$ & $(7.295)$ & $(7.229)$ & $(7.127)$ & $(7.354)$ \\
Managers & 44.99 & 46.41 & 47.63 & 47.04 & 46.82 & 46.31 \\
[0020-0430] & $(7.423)$ & $(8.029)$ & $(8.421)$ & $(8.269)$ & $(8.213)$ & $(7.952)$ \\
Business and financial & 42.20 & 43.74 & 45.03 & 44.54 & 44.45 & 44.19 \\
[0500-0950] & $(5.445)$ & $(6.678)$ & $(7.544)$ & $(7.229)$ & $(7.172)$ & $(6.959)$ \\
Computer and mathematical & 41.34 & 42.58 & 43.90 & 43.47 & 43.23 & 42.94 \\
[1000-1240] & $(4.823)$ & $(5.645)$ & $(6.705)$ & $(6.387)$ & $(6.208)$ & $(5.961)$ \\
Architects and engineers & 42.14 & 43.71 & 44.79 & 44.51 & 44.45 & 44.20 \\
[1300-1530] & $(5.178)$ & $(6.231)$ & $(6.806)$ & $(6.758)$ & $(6.789)$ & $(6.718)$ \\
Scientists & 42.35 & 43.76 & 44.39 & 44.10 & 43.83 & 43.56 \\
[1600-1960] & $(6.029)$ & $(6.935)$ & $(7.435)$ & $(7.142)$ & $(7.033)$ & $(6.837)$ \\
Community and social service & 43.90 & 44.50 & 44.15 & 43.78 & 43.40 & 42.93 \\
{$[2000-2060]$} & $(8.669)$ & $(8.618)$ & $(8.224)$ & $(7.773)$ & $(7.353)$ & $(6.793)$ \\
Legal & 44.80 & 46.88 & 47.67 & 47.45 & 47.19 & 46.72 \\
{$[2100-2150]$} & $(7.117)$ & $(8.115)$ & $(8.789)$ & $(8.894)$ & $(8.894)$ & $(8.693)$ \\
Health care & 44.79 & 45.23 & 45.38 & 44.98 & 44.57 & 44.11 \\
{$[3000-3540]$} & $(10.22)$ & $(10.16)$ & $(10.40)$ & $(10.28)$ & $(9.879)$ & $(9.506)$ \\
N & 371,429 & 539,070 & 704,087 & 450,706 & $1,125,696$ & $1,276,037$
\end{tabular}

The calculations use survey weights. The sample includes full-time (35+ hours per week) workers with a Bachelor's degree between the ages of 22 and 61 who worked 27 weeks or more in the previous year. Standard deviations are in parentheses. The numbers in brackets show the 2010 SOC codes corresponding to each occupational group.

Source: Ruggles et al. (2018): 1980, 1990 and 2000 Census and 2001-2017 American Community Survey. 
Table 2: Elasticity of Annual Earnings with Respect to Usual Weekly Hours

\begin{tabular}{lcccccc}
\hline & 1980 & 1990 & 2000 & $2001-2005$ & $2006-2011$ & $2012-2017$ \\
\hline \hline Teachers & -0.126 & -0.038 & 0.028 & 0.014 & 0.010 & 0.026 \\
& $(0.010)$ & $(0.009)$ & $(0.008)$ & $(0.010)$ & $(0.007)$ & $(0.007)$ \\
Managers & 0.436 & 0.681 & 0.739 & 0.761 & 0.783 & 0.850 \\
& $(0.008)$ & $(0.007)$ & $(0.007)$ & $(0.008)$ & $(0.005)$ & $(0.005)$ \\
Business and financial & 0.610 & 0.735 & 0.913 & 0.961 & 1.024 & 1.104 \\
& $(0.015)$ & $(0.012)$ & $(0.010)$ & $(0.012)$ & $(0.007)$ & $(0.007)$ \\
Computer and mathematical & 0.232 & 0.322 & 0.537 & 0.571 & 0.579 & 0.639 \\
& $(0.031)$ & $(0.020)$ & $(0.013)$ & $(0.016)$ & $(0.011)$ & $(0.010)$ \\
Architects and engineers & 0.353 & 0.366 & 0.421 & 0.419 & 0.434 & 0.435 \\
Scientists & $(0.018)$ & $(0.015)$ & $(0.015)$ & $(0.017)$ & $(0.012)$ & $(0.012)$ \\
Community and social service & 0.308 & 0.365 & 0.396 & 0.480 & 0.472 & 0.453 \\
& $(0.021)$ & $(0.017)$ & $(0.018)$ & $(0.022)$ & $(0.015)$ & $(0.016)$ \\
Legal & -0.057 & 0.044 & 0.109 & 0.214 & 0.198 & 0.209 \\
& $(0.019)$ & $(0.016)$ & $(0.015)$ & $(0.019)$ & $(0.012)$ & $(0.013)$ \\
Health care & 0.449 & 0.798 & 0.817 & 0.891 & 0.943 & 1.000 \\
& $(0.024)$ & $(0.018)$ & $(0.017)$ & $(0.019)$ & $(0.013)$ & $(0.013)$ \\
N & -0.030 & 0.132 & 0.147 & 0.084 & 0.061 & 0.060 \\
& $(0.012)$ & $(0.011)$ & $(0.010)$ & $(0.011)$ & $(0.007)$ & $(0.007)$ \\
\hline
\end{tabular}

Coefficient estimates from regressions of annual earnings on the interaction between occupation group indicators and the natural log of usual weekly hours. Other controls include the natural log of weeks worked, quadratic in age, gender, race and ethnicity, indicator for graduate degree, indicator for working in the private sector, and year and occupation indicators. Standard errors in parentheses. The sample includes full-time (35+ hours per week) workers with a Bachelor's degree between the ages of 22 and 61 who worked 27 weeks or more in the previous year.

Source: Ruggles et al. (2018): 1980, 1990 and 2000 Census and 2001-2017 American Community Survey. 
Table 3: SASS Descriptive Statistics

\begin{tabular}{|c|c|c|}
\hline Variable & Mean & St. dev. \\
\hline School-year base salary (2011 dollars) & $\$ 49,378$ & $\$ 13,052$ \\
\hline School-year earnings from teaching (2011 dollars) & $\$ 51,105$ & $\$ 13,460$ \\
\hline Hours required by contract & 38.16 & 3.45 \\
\hline Hours above contract & 14.71 & 8.58 \\
\hline Continued working as teacher & 0.93 & \\
\hline Teacher motivation & -0.02 & 0.97 \\
\hline Strongly disagree: feel tired & 0.53 & \\
\hline Female & 0.68 & \\
\hline Black & 0.06 & \\
\hline Asian/Pacific Islander/Native American & 0.05 & \\
\hline Hispanic & 0.04 & \\
\hline Teaches any IEP students & 0.88 & \\
\hline Teaches 10 or more IEP students & 0.43 & \\
\hline Union member & 0.71 & \\
\hline Age & 42.27 & 11.38 \\
\hline Years of tenure at current school & 7.86 & 8.27 \\
\hline Years of teaching experience & 13.70 & 10.03 \\
\hline 3 or fewer years of teaching experience & 0.16 & \\
\hline Coach sport & 0.21 & \\
\hline Club sponsor & 0.43 & \\
\hline Department chair & 0.25 & \\
\hline Lead curriculum specialist & 0.11 & \\
\hline District-wide committee & 0.50 & \\
\hline \multicolumn{3}{|l|}{ Class organization } \\
\hline Several classes of different students in 1 or more subjects & 0.651 & \\
\hline One elementary school subject to different classes & 0.029 & \\
\hline Instruct the same group of students in multiple subjects & 0.219 & \\
\hline 1 of 2 or more teachers teaching jointly the same class & 0.034 & \\
\hline Instruct few selected students to address specific needs & 0.068 & \\
\hline Number of different preps (if multiple classes) & 2.75 & 1.56 \\
\hline \multicolumn{3}{|l|}{ Highest grade taught } \\
\hline $\mathrm{K}-5$ & 0.23 & \\
\hline $6-8$ & 0.23 & \\
\hline $9-12$ & 0.53 & \\
\hline \multicolumn{3}{|l|}{ Number of courses in teaching methods: } \\
\hline 0 & 0.09 & \\
\hline 1 or 2 & 0.13 & \\
\hline 3 or 4 & 0.26 & \\
\hline 5 to 9 & 0.28 & \\
\hline 10 or more & 0.24 & \\
\hline \multicolumn{3}{|l|}{ Highest degree earned: } \\
\hline Associates/no college & 0.02 & \\
\hline $\mathrm{BA}$ & 0.49 & \\
\hline Master's & 0.42 & \\
\hline Education Specialist & 0.06 & \\
\hline Ph.D or Ed.D. & 0.01 & \\
\hline
\end{tabular}

Source: U.S. Department of Education, National Center for Education Statistics, Schools and Staffing Survey, 2003-04, 2007-08 and 2011-12. N = 105,290. 
Table 4: Factors Related to Variations in Hours Worked

\begin{tabular}{|c|c|c|c|c|}
\hline \multirow[t]{2}{*}{ Dependent Variable: } & \multicolumn{2}{|c|}{ Hours required by contract } & \multicolumn{2}{|c|}{ Total hours } \\
\hline & $(1)$ & $(2)$ & $(3)$ & $(4)$ \\
\hline \multirow[t]{2}{*}{ Female } & 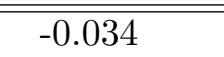 & $\overline{-0.015}$ & $0.339^{* * *}$ & $0.240^{* * *}$ \\
\hline & $(0.025)$ & $(0.026)$ & $(0.065)$ & $(0.070)$ \\
\hline \multirow[t]{2}{*}{ Union member } & $-0.120 * * *$ & -0.024 & $0.562^{* * *}$ & $0.631^{* * *}$ \\
\hline & $(0.026)$ & $(0.029)$ & $(0.067)$ & $(0.079)$ \\
\hline \multirow{2}{*}{ Teaches any IEP students } & 0.032 & -0.020 & $0.260 * * *$ & $0.167^{*}$ \\
\hline & $(0.033)$ & $(0.037)$ & $(0.088)$ & $(0.099)$ \\
\hline \multirow[t]{2}{*}{ Teaches 10 or more IEP students } & $0.061^{* *}$ & $0.060^{* *}$ & $0.263^{* * *}$ & $0.297^{* * *}$ \\
\hline & $(0.024)$ & $(0.026)$ & $(0.063)$ & $(0.071)$ \\
\hline \multirow[t]{2}{*}{ Coach sport } & $0.204^{* * *}$ & $0.195^{* * *}$ & $2.974^{* * *}$ & $2.926^{* * *}$ \\
\hline & $(0.029)$ & $(0.030)$ & $(0.075)$ & $(0.082)$ \\
\hline \multirow[t]{2}{*}{ Club sponsor } & $0.100^{* * *}$ & $0.106^{* * *}$ & $1.471^{* * *}$ & $1.379 * * *$ \\
\hline & $(0.022)$ & $(0.024)$ & $(0.058)$ & $(0.064)$ \\
\hline \multirow[t]{2}{*}{ Department chair } & 0.014 & 0.016 & $0.787^{* * *}$ & $0.755^{* * *}$ \\
\hline & $(0.026)$ & $(0.028)$ & $(0.067)$ & $(0.075)$ \\
\hline \multirow[t]{2}{*}{ Lead curriculum specialist } & 0.025 & 0.036 & $0.951^{* * *}$ & $1.025^{* * *}$ \\
\hline & $(0.034)$ & $(0.037)$ & $(0.090)$ & $(0.099)$ \\
\hline \multirow[t]{2}{*}{ District-wide committee } & $0.119^{* * *}$ & $0.050^{* *}$ & $0.942^{* * *}$ & $0.821 * * *$ \\
\hline & $(0.021)$ & $(0.023)$ & $(0.056)$ & $(0.063)$ \\
\hline \multicolumn{5}{|c|}{ Highest grade taught (excluded: $12^{\text {th }}$ ) } \\
\hline \multirow{2}{*}{ Pre-K } & -0.053 & 0.095 & $-1.971^{* * *}$ & $-2.519 * * *$ \\
\hline & $(0.232)$ & $(0.263)$ & $(0.611)$ & $(0.710)$ \\
\hline \multirow[t]{2}{*}{ Kindergarten } & -0.001 & 0.023 & $-1.778^{* * *}$ & $-1.852^{* * *}$ \\
\hline & $(0.091)$ & $(0.105)$ & $(0.240)$ & $(0.285)$ \\
\hline \multirow[t]{2}{*}{$1^{\mathrm{st}}$} & -0.022 & -0.047 & $-0.634^{* * *}$ & $-0.811^{* * *}$ \\
\hline & (0.088) & $(0.102)$ & $(0.231)$ & $(0.275)$ \\
\hline \multirow[t]{2}{*}{$2^{\text {nd }}$} & 0.001 & 0.010 & $-0.884^{* * *}$ & $-0.912^{* * *}$ \\
\hline & $(0.085)$ & $(0.098)$ & $(0.222)$ & $(0.266)$ \\
\hline \multirow[t]{2}{*}{$3^{r d}$} & -0.018 & -0.070 & $-0.907^{* * *}$ & $-1.045^{* * *}$ \\
\hline & $(0.084)$ & $(0.097)$ & $(0.220)$ & $(0.263)$ \\
\hline \multirow[t]{2}{*}{$4^{\text {th }}$} & -0.055 & -0.039 & $-0.900 * * *$ & $-1.113^{* * *}$ \\
\hline & $(0.082)$ & $(0.095)$ & $(0.216)$ & $(0.258)$ \\
\hline \multirow[t]{2}{*}{$5^{\text {th }}$} & -0.075 & -0.053 & $-1.191 * * *$ & $-1.402 * * *$ \\
\hline & $(0.071)$ & $(0.083)$ & $(0.185)$ & $(0.225)$ \\
\hline \multirow[t]{2}{*}{$6^{\text {th }}$} & -0.029 & -0.032 & $-1.463^{* * *}$ & $-1.732^{* * *}$ \\
\hline & $(0.063)$ & $(0.073)$ & $(0.166)$ & $(0.197)$ \\
\hline \multirow[t]{2}{*}{$7^{\text {th }}$} & 0.019 & -0.054 & $-0.817^{* * *}$ & $-1.030^{* * *}$ \\
\hline & $(0.067)$ & $(0.076)$ & $(0.175)$ & $(0.205)$ \\
\hline \multirow[t]{2}{*}{$8^{\text {th }}$} & 0.068 & 0.068 & $-0.887^{* * *}$ & $-1.054^{* * *}$ \\
\hline & $(0.053)$ & $(0.062)$ & $(0.139)$ & $(0.167)$ \\
\hline $9^{\text {th }}$ & 0.038 & -0.023 & $-0.820 * * *$ & $-1.056^{* * *}$ \\
\hline & $(0.058)$ & $(0.070)$ & $(0.153)$ & $(0.189)$ \\
\hline $10^{\text {th }}$ & -0.073 & -0.046 & $-0.557^{* * *}$ & $-0.574^{* * *}$ \\
\hline & $(0.062)$ & $(0.065)$ & $(0.162)$ & $(0.176)$ \\
\hline $11^{\text {th }}$ & 0.087 & 0.052 & -0.219 & -0.252 \\
\hline & $(0.056)^{46}$ & $(0.059)$ & (0.148) & $(0.159)$ \\
\hline
\end{tabular}




\begin{tabular}{|c|c|c|c|c|}
\hline \multicolumn{5}{|l|}{ Subject (excluded: Other) } \\
\hline \multirow[t]{2}{*}{ Early Childhood or General Elementary } & $0.161^{*}$ & 0.139 & $3.047^{* * *}$ & $2.617^{* * *}$ \\
\hline & $(0.086)$ & $(0.094)$ & $(0.227)$ & $(0.253)$ \\
\hline \multirow[t]{2}{*}{ Special Education } & $-0.193^{* *}$ & $-0.183^{* *}$ & -0.173 & $-0.482^{* *}$ \\
\hline & $(0.080)$ & $(0.085)$ & $(0.209)$ & $(0.230)$ \\
\hline \multirow[t]{2}{*}{ Arts and Music } & 0.010 & -0.012 & 0.027 & -0.108 \\
\hline & $(0.083)$ & $(0.088)$ & $(0.218)$ & $(0.237)$ \\
\hline \multirow[t]{2}{*}{ English and Language Arts } & 0.018 & 0.043 & $1.858^{* * *}$ & $1.814^{* * *}$ \\
\hline & $(0.077)$ & $(0.081)$ & $(0.202)$ & $(0.219)$ \\
\hline \multirow[t]{2}{*}{ ESL or Bilingual Education } & -0.155 & -0.114 & 0.431 & 0.197 \\
\hline & $(0.131)$ & $(0.140)$ & $(0.344)$ & $(0.378)$ \\
\hline \multirow[t]{2}{*}{ Foreign Languages } & -0.077 & -0.069 & $0.671^{* * *}$ & 0.382 \\
\hline & $(0.091)$ & $(0.096)$ & $(0.240)$ & $(0.258)$ \\
\hline \multirow[t]{2}{*}{ Health or Physical Education } & 0.009 & 0.003 & 0.010 & -0.121 \\
\hline & $(0.084)$ & $(0.089)$ & $(0.221)$ & $(0.240)$ \\
\hline \multirow[t]{2}{*}{ Mathematics } & $-0.164^{* *}$ & $-0.150^{*}$ & $0.661^{* * *}$ & $0.499 * *$ \\
\hline & $(0.078)$ & $(0.082)$ & $(0.204)$ & $(0.221)$ \\
\hline \multirow[t]{2}{*}{ Natural Sciences } & -0.037 & -0.014 & $1.917^{* * *}$ & $1.731^{* * *}$ \\
\hline & $(0.079)$ & $(0.083)$ & $(0.207)$ & $(0.224)$ \\
\hline \multirow{2}{*}{ Social Sciences } & -0.038 & 0.017 & $1.757^{* * *}$ & $1.608^{* * *}$ \\
\hline & $(0.079)$ & $(0.083)$ & $(0.208)$ & $(0.225)$ \\
\hline \multirow[t]{2}{*}{ Vocational, Career, or Technical Education } & -0.107 & -0.099 & -0.280 & -0.282 \\
\hline & $(0.079)$ & $(0.084)$ & $(0.208)$ & $(0.228)$ \\
\hline \multirow[t]{2}{*}{ Teaches multiple classes } & 0.002 & 0.017 & $0.491^{* * *}$ & $0.436^{* *}$ \\
\hline & $(0.057)$ & $(0.064)$ & $(0.151)$ & $(0.173)$ \\
\hline \multirow[t]{2}{*}{ Number of different preps } & -0.004 & 0.006 & $0.074^{* * *}$ & $0.074^{* *}$ \\
\hline & $(0.010)$ & $(0.011)$ & $(0.027)$ & $(0.031)$ \\
\hline \multirow[t]{2}{*}{ Number of different sections } & $0.019^{* *}$ & 0.005 & -0.023 & $-0.045^{*}$ \\
\hline & $(0.009)$ & $(0.010)$ & $(0.023)$ & $(0.026)$ \\
\hline \multirow[t]{2}{*}{ Master's degree } & -0.026 & -0.040 & $-0.240 * * *$ & $-0.279 * * *$ \\
\hline & $(0.023)$ & $(0.025)$ & $(0.060)$ & $(0.067)$ \\
\hline \multirow[t]{2}{*}{ Certificate of Advanced Graduate Studies } & -0.065 & -0.073 & $0.203^{*}$ & 0.191 \\
\hline & $(0.046)$ & $(0.049)$ & $(0.120)$ & $(0.132)$ \\
\hline \multirow[t]{2}{*}{$\mathrm{PhD}$ or Professional degree } & -0.071 & -0.029 & 0.341 & 0.179 \\
\hline & $(0.100)$ & $(0.105)$ & $(0.262)$ & $(0.284)$ \\
\hline \multicolumn{5}{|c|}{ Number of courses in teaching methods (excluded: 0 courses) } \\
\hline \multirow[t]{2}{*}{1 or 2 courses } & -0.050 & -0.035 & 0.006 & 0.047 \\
\hline & $(0.044)$ & $(0.047)$ & $(0.116)$ & $(0.126)$ \\
\hline \multirow[t]{2}{*}{3 or 4 courses } & 0.033 & 0.039 & $0.428^{* * *}$ & $0.441^{* * *}$ \\
\hline & $(0.040)$ & $(0.042)$ & $(0.104)$ & $(0.114)$ \\
\hline \multirow[t]{2}{*}{5 to 9 courses } & 0.030 & 0.042 & $0.731^{* * *}$ & $0.744^{* * *}$ \\
\hline & $(0.040)$ & $(0.042)$ & $(0.104)$ & $(0.114)$ \\
\hline \multirow[t]{2}{*}{10 or more courses } & 0.050 & 0.054 & $1.288^{* * *}$ & $1.263^{* * *}$ \\
\hline & $(0.041)$ & $(0.044)$ & $(0.108)$ & $(0.119)$ \\
\hline School fixed effects & No & Yes & No & Yes \\
\hline
\end{tabular}

${ }^{*} \mathrm{p}<0.10,{ }^{* *} \mathrm{p}<0.05,{ }^{* * *} \mathrm{p}<0.01$. The models include quadratics in experience and tenure and indicators for each of the first 3 years of experience and tenure, as well as indicators for survey year. The models without school fixed effects include school-level controls for school type (elementary, middle or high) and size, the student-to-teacher ratio, the fraction of minority students and teachers at the school, the share of students who qualify for free or reduced-price lunch, an indicttor for charter school, and state dummies. The errors are clustered at the district level. $\mathrm{N}=105,290$.

Source: U.S. Department of Education, National Center for Education Statistics, Schools and Staffing Survey, 2003-04, 2007-08 and 2011-12. 
Table 5: Relationship between Annual Earnings and Hours for Teachers in the SASS

\begin{tabular}{|c|c|c|c|}
\hline \multirow[t]{2}{*}{ Dependent Variable: } & \multicolumn{2}{|c|}{ Ln(total salary) } & \multirow{2}{*}{$\begin{array}{c}\text { Ln(base salary) } \\
(3)\end{array}$} \\
\hline & (1) & $(2)$ & \\
\hline$\overline{\mathrm{Ln}(\text { Total hours }) \times 2003}$ & $\begin{array}{c}0.0183^{* * *} \\
(0.0053)\end{array}$ & & \\
\hline $\operatorname{Ln}($ Total hours $) \times 2007$ & $\begin{array}{c}0.0205^{* * *} \\
(0.0060)\end{array}$ & & \\
\hline $\operatorname{Ln}($ Total hours $) \times 2011$ & $\begin{array}{l}0.0111^{*} \\
(0.0062)\end{array}$ & & \\
\hline Hours required by contract $(\times 10)$ & & $\begin{array}{l}-0.0036 \\
(0.0022)\end{array}$ & $\begin{array}{c}-0.0049^{* *} \\
(0.0022)\end{array}$ \\
\hline Hours above contract $(\times 10)$ & & $\begin{array}{c}0.0037^{* * *} \\
(0.0006)\end{array}$ & $\begin{array}{c}-0.0026^{* * *} \\
(0.0006)\end{array}$ \\
\hline Extracurricular activities: & & & \\
\hline Coach sport & $\begin{array}{c}0.0398^{* * *} \\
(0.0016)\end{array}$ & $\begin{array}{c}0.0398^{* * *} \\
(0.0017)\end{array}$ & $\begin{array}{c}-0.0098^{* * * *} \\
(0.0015)\end{array}$ \\
\hline Club sponsor & $\begin{array}{c}0.0014 \\
(0.0012)\end{array}$ & $\begin{array}{c}0.0014 \\
(0.0012)\end{array}$ & $\begin{array}{c}-0.0049 * * * \\
(0.0011)\end{array}$ \\
\hline Department chair & $\begin{array}{c}0.0040^{* * *} \\
(0.0014)\end{array}$ & $\begin{array}{c}0.0040^{* * * *} \\
(0.0014)\end{array}$ & $\begin{array}{l}-0.0016 \\
(0.0013)\end{array}$ \\
\hline Lead curriculum specialist & $\begin{array}{c}0.0120^{* * *} \\
(0.0018)\end{array}$ & $\begin{array}{c}0.0119^{* * * *} \\
(0.0018)\end{array}$ & $\begin{array}{c}0.0090^{* * *} \\
(0.0017)\end{array}$ \\
\hline District-wide committee & $\begin{array}{c}0.0068^{* * *} \\
(0.0012)\end{array}$ & $\begin{array}{c}0.0068^{* * *} \\
(0.0012)\end{array}$ & $\begin{array}{c}0.0054^{* * *} \\
(0.0011)\end{array}$ \\
\hline
\end{tabular}

${ }^{*} \mathrm{p}<0.10,{ }^{* *} \mathrm{p}<0.05,{ }^{* * *} \mathrm{p}<0.01$. Total salary includes school year earnings from bonuses and extracurricular activities. The models include the controls from Table 3; quadratics in experience and tenure and indicators for each of the first 3 years of experience and tenure; indicators for subjects taught; survey year indicators; school-level controls for school type (elementary, middle or high) and size, the student-to-teacher ratio, the fraction of minority students and teachers at the school, the share of students who qualify for free or reduced-price lunch, an indicator for charter school, and state dummies. The errors are clustered at the district level. $\mathrm{N}=105,290$.

Source: U.S. Department of Education, National Center for Education Statistics, Schools and Staffing Survey, 2003-04, 2007-08 and 2011-12. 


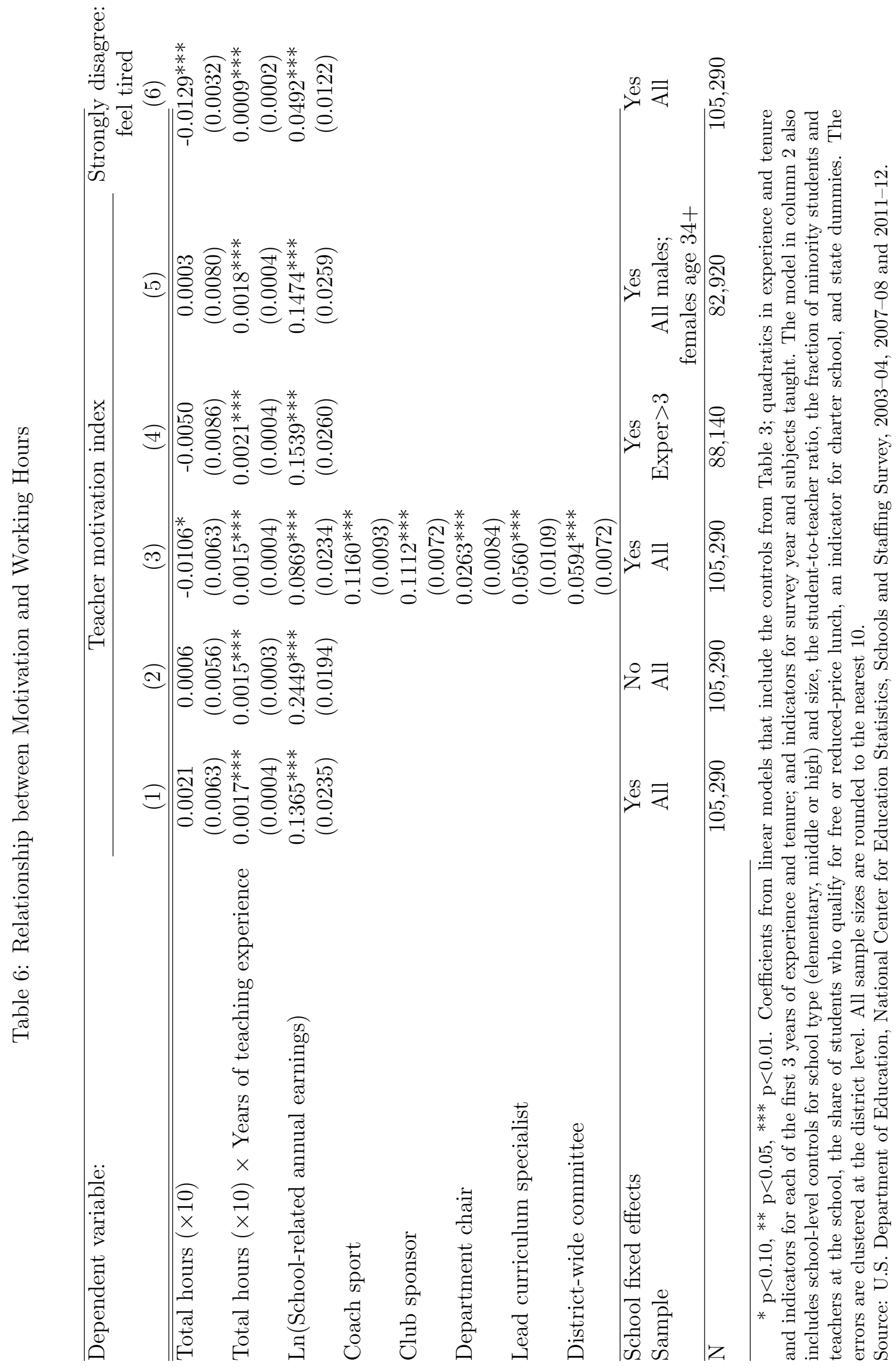




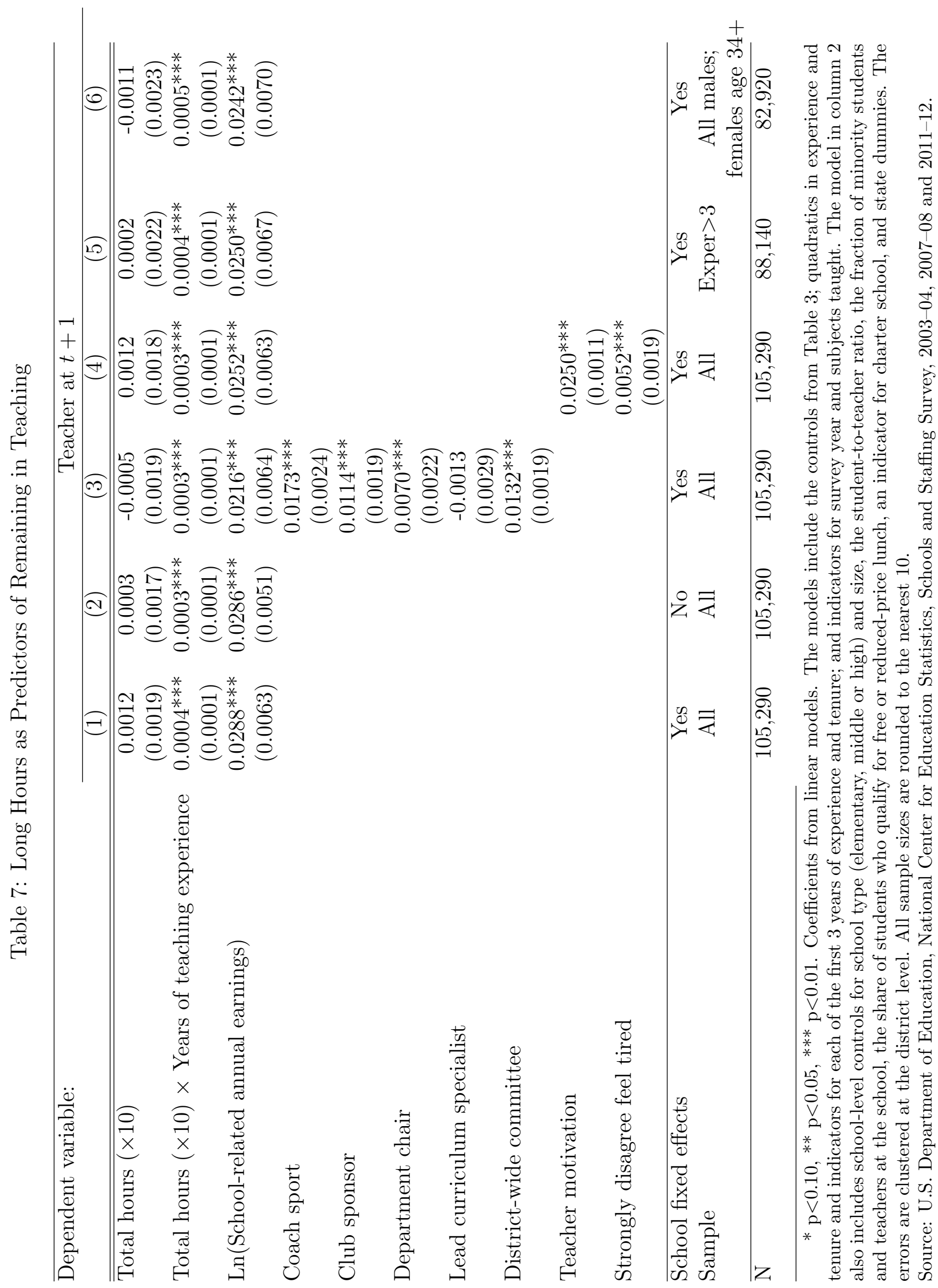




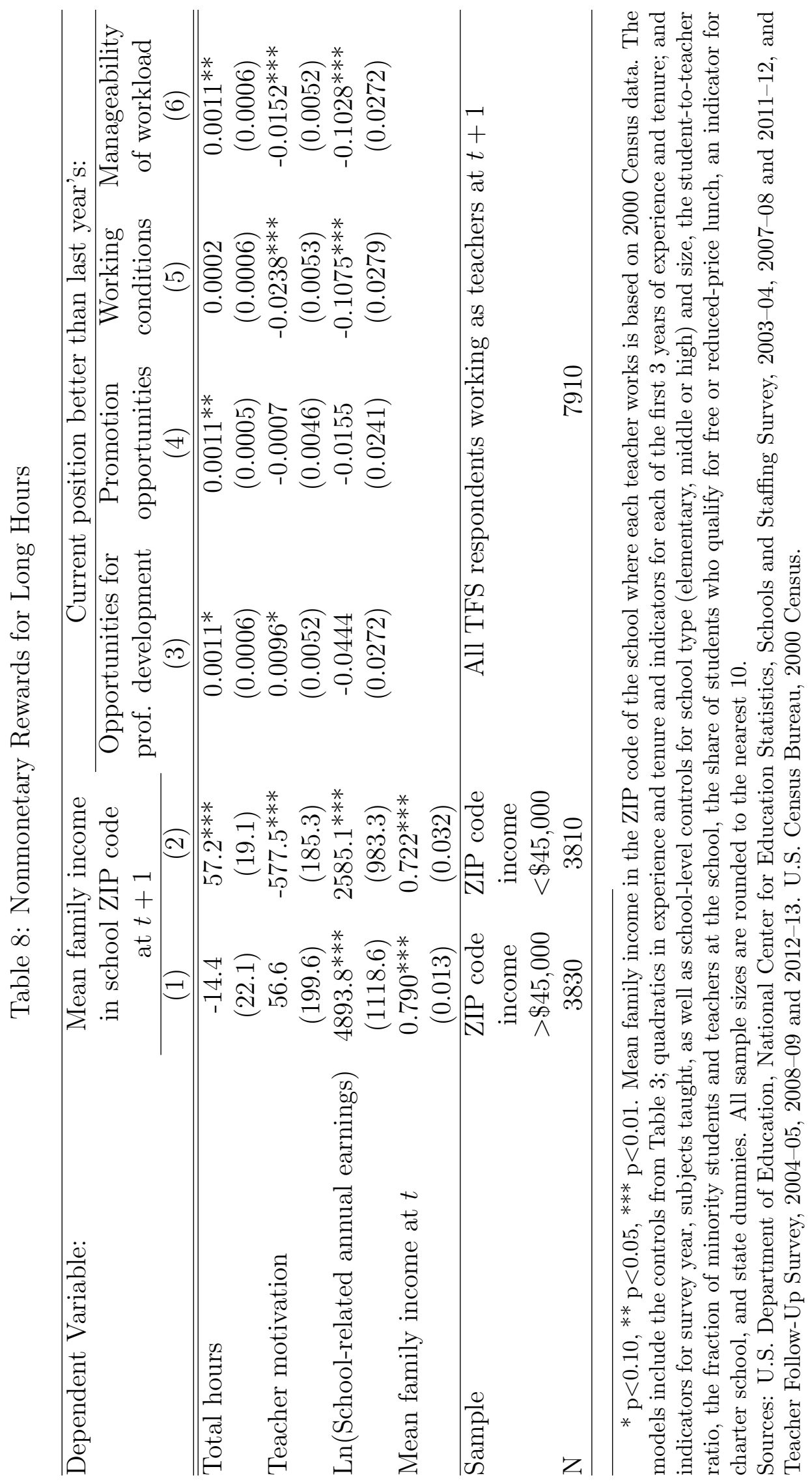


Table 9: Results by School Type

\begin{tabular}{|c|c|c|c|c|}
\hline \multirow[t]{2}{*}{ Dependent Variable: } & \multicolumn{2}{|c|}{ Teacher at $t+1$} & \multicolumn{2}{|c|}{ Teacher motivation } \\
\hline & (1) & $(2)$ & (3) & (4) \\
\hline \multicolumn{5}{|c|}{ A. Results by Free or Reduced Lunch Status } \\
\hline Total hours $(\times 10)$ & $\begin{array}{l}-0.0037 \\
(0.0030)\end{array}$ & $\begin{array}{c}0.0033 \\
(0.0032)\end{array}$ & $\begin{array}{l}-0.0139 \\
(0.0110)\end{array}$ & $\begin{array}{c}0.0087 \\
(0.0105)\end{array}$ \\
\hline Total hours $(\times 10) \times$ Experience & $\begin{array}{c}0.0006^{* * *} \\
(0.0002)\end{array}$ & $\begin{array}{c}0.0002 \\
(0.0002)\end{array}$ & $\begin{array}{c}0.0021^{* * *} \\
(0.0006)\end{array}$ & $\begin{array}{l}0.0010^{*} \\
(0.0006)\end{array}$ \\
\hline Ln(School-related annual earnings) & $\begin{array}{c}0.0258^{* *} \\
(0.0106)\end{array}$ & $\begin{array}{c}0.0449^{* * *} \\
(0.0121)\end{array}$ & $\begin{array}{c}0.1456^{* * *} \\
(0.0386)\end{array}$ & $\begin{array}{c}0.1433^{* * *} \\
(0.0412)\end{array}$ \\
\hline$\%$ free or reduced lunch & $<25 \%$ & $>50 \%$ & $<25 \%$ & $>50 \%$ \\
\hline $\mathrm{N}$ & 34160 & 35700 & 34160 & 35700 \\
\hline \multicolumn{5}{|l|}{ B. Results by School Level } \\
\hline Total hours $(\times 10)$ & $\begin{array}{c}0.0038 \\
(0.0030)\end{array}$ & $\begin{array}{l}-0.0006 \\
(0.0026)\end{array}$ & $\begin{array}{c}0.0049 \\
(0.0107)\end{array}$ & $\begin{array}{c}0.0010 \\
(0.0088)\end{array}$ \\
\hline Total hours $(\times 10) \times$ Experience & $\begin{array}{c}0.0002 \\
(0.0002)\end{array}$ & $\begin{array}{c}0.0005^{* * *} \\
(0.0002)\end{array}$ & $\begin{array}{c}0.0004 \\
(0.0006)\end{array}$ & $\begin{array}{c}0.0023^{* * *} \\
(0.0005)\end{array}$ \\
\hline Ln(School-related annual earnings) & $\begin{array}{c}0.0124 \\
(0.0103)\end{array}$ & $\begin{array}{c}0.0431^{* * *} \\
(0.0091)\end{array}$ & $\begin{array}{c}0.0482 \\
(0.0386)\end{array}$ & $\begin{array}{c}0.1990^{* * *} \\
(0.0315)\end{array}$ \\
\hline School level & $\begin{array}{l}\text { Elem.\& } \\
\text { Middle }\end{array}$ & High & $\begin{array}{l}\text { Elem.\& } \\
\text { Middle }\end{array}$ & High \\
\hline $\mathrm{N}$ & 43610 & 49450 & 43610 & 49450 \\
\hline
\end{tabular}

${ }^{*} \mathrm{p}<0.10,{ }^{* *} \mathrm{p}<0.05,{ }^{* * *} \mathrm{p}<0.01$. The models include school fixed effects as well as the controls from Table 3; quadratics in experience and tenure and indicators for each of the first 3 years of experience and tenure; and indicators for survey year and subjects taught. The errors are clustered at the district level. Schools for which the share of students receiving free or reduced lunch is missing are excluded from Panel A. Schools whose level is listed as "combined" are excluded from Panel B. All sample sizes are rounded to the nearest 10.

Source: U.S. Department of Education, National Center for Education Statistics, Schools and Staffing Survey, 2003-04, 2007-08 and 2011-12. 


\section{Appendix A}

Proof that $m^{\prime}(t)>0$

Note that

$$
m(t)=\frac{P_{m}(t)}{P_{m}(t)+P_{l}(t)}
$$

Since

$$
P_{s}^{\prime}(t)=\ln \left[F\left(\tilde{w}+\gamma_{s} V\left(e_{s}^{*}\right)-C\left(e_{s}^{*}\right)\right)\right] P_{s}(t),
$$

it holds that

$$
m^{\prime}(t)=\frac{P_{m}^{\prime}(t) P_{l}(t)-P_{m}(t) P_{l}^{\prime}(t)}{\left(P_{m}(t)+P_{l}(t)\right)^{2}}
$$

or

$$
m^{\prime}(t)=\frac{P_{m}(t) P_{l}(t)\left(\ln p_{m}-\ln p_{l}\right)}{\left(P_{m}(t)+P_{l}(t)\right)^{2}}>0
$$

because $p_{m}>p_{l}$.

Proof that $\bar{a}^{\prime}(t)<0$

It holds that

$$
\bar{a}^{\prime}(t)=R_{m}^{\prime}(t)\left[\left(1-p_{m}\right) a_{h}-\left(1-p_{l}\right) a_{l}\right]+R_{r}^{\prime}(t)\left[\left(1-p_{r}\right) a_{h}-\left(1-p_{l}\right) a_{l}\right]
$$

It is the case that

$$
R_{m}^{\prime}(t)=\frac{P_{m}(t)\left[P_{r}(t)\left(\ln \left(p_{m}\right)-\ln \left(p_{r}\right)\right)+P_{l}(t)\left(\ln \left(p_{m}\right)-\ln \left(p_{l}\right)\right)\right]}{\left(P_{m}(t)+P_{r}(t)+P_{l}(t)\right)^{2}}>0
$$

while

$$
R_{r}^{\prime}(t)=\frac{P_{r}(t)\left[P_{m}(t)\left(\ln \left(p_{r}\right)-\ln \left(p_{m}\right)\right)+P_{l}(t)\left(\ln \left(p_{r}\right)-\ln \left(p_{l}\right)\right)\right]}{\left(P_{m}(t)+P_{r}(t)+P_{l}(t)\right)^{2}}<0
$$


when $p_{r}<p_{l}<p_{m}$. In addition, $\left(1-p_{r}\right) a_{h}>\left(1-p_{l}\right) a_{l}$, so $\left(1-p_{m}\right) a_{h}<\left(1-p_{l}\right) a_{l}$ is a sufficient condition for $\bar{a}^{\prime}(t)<0$.

\section{Appendix B}

\section{Factor Loadings for the Teacher Motivation Index}

\begin{tabular}{lc}
\hline Would become teacher if starting over & 0.459 \\
Plans to remain in teaching as long as possible & 0.482 \\
As much enthusiasm as when began teaching & 0.526 \\
Stay in teaching even if higher paying job available & 0.529 \\
\hline Eigenvalue & 1.998
\end{tabular}

Factor loadings from principal component analysis. $\mathrm{N}=105,290$.

Source: U.S. Department of Education, National Center for Education Statistics, Schools and Staffing Survey, 2003-04, 2007-08 and 2011-12. 


\section{Appendix C}

\section{Teacher Motivation by Cohort}

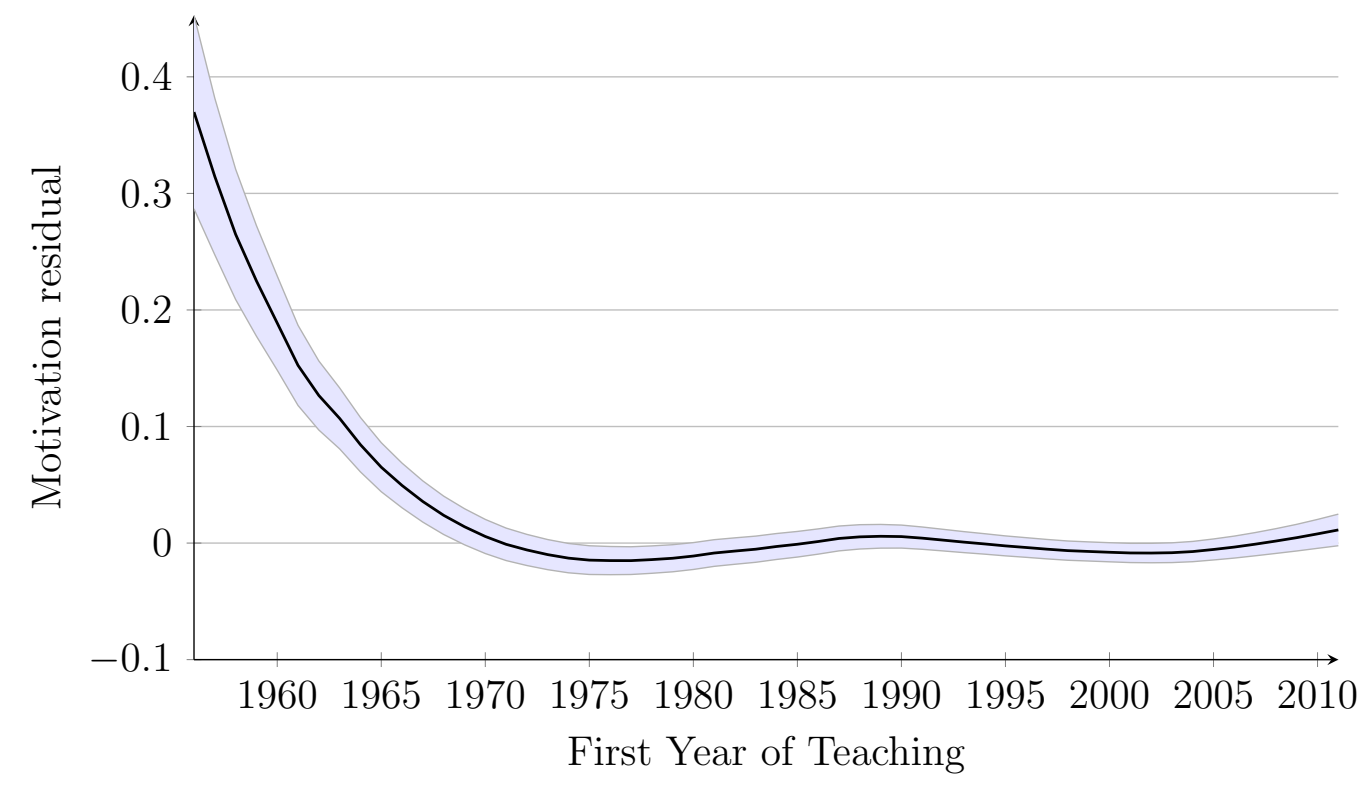

Local polynomial regression results. The residuals are obtained from regressions of the teacher motivation index described in Section 4 on indicators for subjects and highest grade taught, a quadratic in teaching experience and indicators for the first 3 years of experience, indicators for survey year, and school-level controls for school type (elementary, middle or high) and size, the student-to-teacher ratio, the fraction of minority students and teachers at the school, the share of students who qualify for free or reduced-price lunch, an indicator for charter school, and state dummies.

Source: U.S. Department of Education, National Center for Education Statistics, Schools and Staffing Survey, 2003-04, 2007-08, and 2011-12. 